\title{
Italienische Vulgärnamen der Fledermaus.
}

Bei einer Tiergruppe die, wie die Fledermäuse, nur geringe Beziehungen zu dem Menschen hat, ist es erklärlich, dafs die Namen, welche das Volk ihnen gibt, sich beinahe ohne Ausnahme nicht auf einzelne Arten beziehen, sondern auf die gesamte Ordnung. Im Fluge - und wie viele Menschen haben die Fledermäuse je anders beobachtet? - sehen eben alle einander mehr oder weniger gleich. Um so auffallender muls es erscheinen, dafs die Bezeichnungen der italienischen Mundarten für die Fledermaus so zahlreich sind; der Grund daran wird gerade die geringe Bekanntschaft mit diesen Tieren sein, und das Geheimnifsvolle, womit sie infolgedessen in den Augen des Volkes umgeben sind. Einen ähnlichen Reichtum finden wir in den slavischen Sprachen ${ }^{1}$, während die Armut des Deutschen an volkstümlichen Benennungen der Fledermaus dagegen in bemerkenswerter Weise absticht.

Zum Teil sind, wie wir gleich sehen werden, die volkstümlichen Namen des heutigen Italiens freilich nichts anderes als mehr oder weniger weit gediehene Entstellungen des griechischen vvxtepis (eigentlich Nachttier) und des lateinischen vespertilio (Abendtier), ihrem Sinne nach sehr allgemein gehaltenen Bezeichnungen.

Von vespertilio:

Sassorosso di Garfagnana (Prov. Massa): spertello; Porto di Civitanuova u. s. f. (Prov. Macerata), spiridillo; Marken, spiriticolo; Caserta, sportiglione; Neapel und Umgegend, sportigliiun; Iglesias (Sardinien), pistellus; Toscana, vipistrello, vispistrello, pipistrello; Florenz, pripistello; S. Domenico b. Florenz, primpistello; Figline (Vald'Arno), pimpistrello; Prov. Pisa, pilistrello, pilustrello; Castelfiorentino (Prov. Firenze), pilustrello; Lucca pilistrello ${ }^{2}$ ); Tenerano (Pr. Massa), papastrello; Equi (Massa), papastrel; Frassinoro (Modena), paipastrello; Premilcuore (Romagna Toscana), baibastrel; Parma, pálpdstrel; Parma, parpastrell 3; S. Paolo d'Enza (Reggio Emilia), palpastrell; Mantov. Bol. Mod., palpastrell ${ }^{3}$; Castelnuovo nei Monti (Reggio Emilia), pal-

1 Frans Miklosich, Etymol. Wörterbuch d. slav. Sprachen. Wien 1886.

2 Silvio Peri, Fonetica del Dialetto lucchese (A. G. I. XII p. 107-134).

- Adolf Mussafia, Beitrag zur Kunde der norditalien. Mundarten im XV. Jahrh. Wien 1873 (Aus d. XXII. Bde. d. Denkschr. d. Philos.-histor. Classe d. K. Acad. d. Wiss.) p. 32, s. v. barbastrello. 
pastrél, polpastrel; Imola (Bologna), balbastre; Mant. rmg. balbastrell; ${ }^{1}$ Mirandola, palpastrell, pappastrell 2; Ferrara, barbastie, balbastrell, barbastell; Padova, barbastrkgio; Vened. ant. barbastregio ${ }^{3}$; barbastelo 4 , barbastrigio ${ }^{5}$; barbastrigo, barbastrillo; Friaul, barbastrin; barbastin ${ }^{6}$, barbastel7; ital. Tyrol, barbustell.

Diese Abänderungen von vespertilio finden sich demnach mit wenigen Ausnahmen in einer Zone, die von Toscana ausgehend, sich nach Nordosten bis zur Grenze des italienischen Sprachgebietes erstreckt. Flechia hält es für sehr wahrscheinlich, dafs vespertilio im Laufe der Zeit eine Assimilation des j (i) mit dem vorausgehenden 1 erlitten habe, also vespertilio, vespertiljo, vespertillo, vespertello, vipistrello, pipistrello ${ }^{8}$. Als Belege für die Existenz von vespertilio in der Volkssprache betrachtet derselbe sportiglione und barbastregio, welches letztere sich mit seiner Endung zu vespertilio verhalte, wie z. B. pavegio zu papilio. Aus dem oben mitgeteilten Verzeichnis ergibt sich, das vespertillo bezeugt ist durch spiridillo, und vespertello durch spertello, pistellus und barbustell u.s.w.; dagegen dürften die toscanischen pripistello und primpistello nur nachträgliche Entstellungen von pipistrello sein.

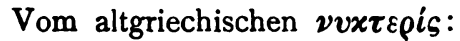

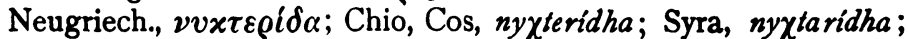
Kalymnos, nyxtiria (plur. -ies); Mesaria (Icaria), lycteridha; Icaria, lyxderidha; Olymbos (Karpathos), lyxtartdha; Candia, lactaridha; Bova (Reggio Cal.), laftarida: (Morosi hat lastarida' ${ }^{9}$ ); Roccaforte (Reggio Cal.), laftaride, lefterida; Neapel, tagddariti; 10 Calabr., taddarito; 11 Oppido (Pr. Catanzaro), tagliarita; Palmi (Reggio Cal.), tallarito, taddarito; S. Eufemia (Cal.), taraddino; Sicilien, tardarita, tardaritola; 12 Messina, taddarichi; Condofuri (Reggio Cal.), taddarida; Reggio Cal, taddarita; Modica (Sicil.), taddariti; Palermo, taddarita.

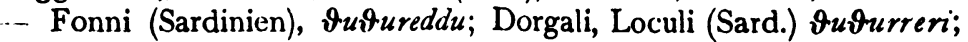
Aritzo (Sard.), sunzuritos; Quartu S. Elena, Villasimius, Barumini (Sard.) zurrundéddu (plur. -us); Oliena, Nuoro (Sard.) tzutzurreri; Quartu S. Elena, Sinnai (Sard.), zurundelli. -

1 Mussafua, 1. c.

2 E. Meschieri, Vocabolario Mirandolese-Italiano. Bologna 1876.

3 G. Boerio, Dizion. del Dial. Veneziano. Sec. Ed. Venezia 1856.

- $i b . \quad 5 i b . \quad B$ fac. Pirona, Voc. friulano. Venezia 1871. ${ }^{7} i b$.

8 G. Flechia, "Sull' orgine dell'unica forma flessionale del nome italiano, studio di Francesco D'Ovidio, Pisa 1872 " (Rivista di filologia e d'istruzione classica I, 1873. Torino p. 94).

- G. Morosi, Dialetti Romaici del Mandamento di Bova in Calabria (Arch. Glottol. Ital. IV) 1878.

10 O. G. Costa, Fauna del Regno di Napoli 1839 p. 5.

$11 O$. G. Costa, Vocabolario Zoologico comprendente le voci volgari con cui in Napoli ed in altre contrade del regno appellansi animäli o parti di essi. Napoli 1846. s. v.

12 Traina, Vocabolarietto delle Voci Siciliane. Torino 1877 , s. v.; derselbe fügt bei: ,forse da tardi per sera sp. tardes; come da notte nottola. $E$ in latino infatti vespertilio da vesperus." Die Form tardarita wird Volksetymologie sein, 
Die Bezeichnungen von den griechischen Inseln vermitteln

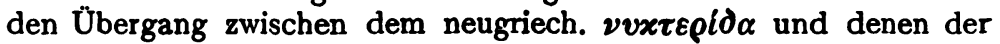
neugriechischen Colonien Calabriens. ${ }^{1}$ Die neapolitanischen und sicilianischen tagdarita u. s. f. lassen sich ohne Schwierigkeit auf lactaridha oder etwas Ähnliches zurückführen, wenn wir annehmen, dafs das auslautende 1 in $t$ verwandelt worden sei, behufs Erzielung einer Art Reduplication, welche dann in taddarita vollständig geworden ist. Nichtsdestoweniger ist nicht ausgeschlossen, dafs die erwähnten süditalienischen Namen ein Erbtum aus der Zeit Grolsgriechenlands sind, die Endung -ita wäre dann selbständig entstanden, also keine Ableitung aus dem neugriechischen $-i \delta \alpha$. Die sardischen Benennungen mögen secundär aus taddarita entstanden sein; der Weg ist freilich weit von vvxecpis zu zurundelli, und dennoch, wenn wir namentlich lactaridha und tagdarida einerseits, taddarita und $\vartheta u \vartheta u r e d d u$ andrerseits ins Auge fassen, so ergibt sich ein unmerklicher Übergang der verschiedenen Formen in einander, $\alpha \nu \dot{\alpha}^{\prime} \tau^{\prime} \dot{\alpha}^{\prime} \lambda \lambda \dot{\eta}^{\prime} \lambda \eta \sigma \iota \nu$ '̌́ $\chi 0 \nu \tau \alpha \iota$.

Etymologisch nicht, wohl aber logisch, schliessen sich an

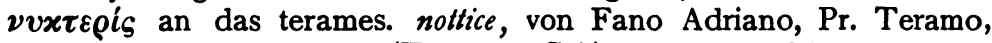
und das calabr. notturna (Taverna, Cal.), sowie die folgenden Ableitungen aus noctua, vermittelst eines ${ }^{*}$ noctula: ${ }^{2}$

Umbria (XIV. Jahr.) noctola ${ }^{3}$; Toscana, nottolo, nottola, nottolone; Macerata, nottola; Sinigaglia, nottula; Lunigiana, nottolo; Venezia, nottolo, nottolino, nottolone 4 ; Pieve di Cadoro, nótol; Friaul, nöttöl, gnótul; Ladin. (Unterfassa) nótulo; ${ }^{5}$ Lad. (Avoltri), notol; ${ }^{6} \mathrm{Lad}$, (Cormons), nyotul ; ${ }^{7}$ Ladinien, noettora, nettora; 8 Lad. (Buchenstein). nettola; ${ }^{9}$ Lad. (Abtei), netora; ${ }^{10}$ Lad. (Fassa), nettora; 11 Lad. (Ampezzo), nuottora; 12 Frataguida (Umbria), nottolella; Valtellina, nucireula; Valtell. (Sondrio), nuciareula; Valtell. nociroeula; 13 Valtell. (Tirano), nociardeula; 14 Poschiavo, noitaroeula; ${ }^{15}$ Tre Pievi (Como), gólanócc, 16 für volanocc; denen sich scürott (Gebiet von Fanano, Prov. Modena) anreihen mag, da es doch wohl von scuro, dunkel, Dunkelheit abzuleiten ist.

1 In Betreff des $f$ dieser letztern vergl. Comparetti, Saggio dei Dialetti

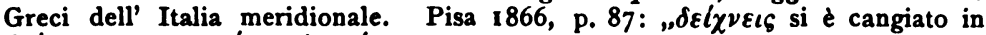

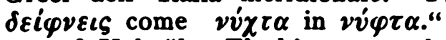

2 Vgl. übr. Flechia: "nottola sta per nottova (noctua)“. Post. Etim. (A. G. I. III, 1878).

8 Atti Accad. Lincei. 1889. Rendiconti p. 718 fgg.

- A. P. Ninni, Materiali per la fauna Veneta (Estr. dal Vol. IV Ser. V degli Atti del R. Ist. Veneto di Scienze, lettere ed arti, Venezia 1878. p. 6 Nota 1 .

${ }_{5}$ Th. Gartner, Die raetoroman. Mundarten (Gröber, Grundr. d. rom. Philologie I p. 470). $\quad$ id. $2 b . \quad 7$ id. $i b$.

8 Foh. Alton, Die ladin. Idiome in Ladinien, Gröden, Fassa, Buchenstein, Ampezzo. - Innsbruck, 1879.

id. 26. 10 Th. Gartner, 1. c.

11 Alton, 1. c. 12 Alton, 1. c.

18 P. Monti, Vocabol. dei Dialetti della Città e Diocesi di Como u.s.w. Milano, 1845. 14 id. ib. 15 id. ib. 16 id. $i b$. 
Bisweilen werden die Fledermäuse für Schmetterlinge gehalten, häufiger für Vögel; daher einerseits :

Lanusei (Sardin.), papilio de nocte; Vinca, Tenerano (Massa), parpaglione; Equi (Massa), parpaglión; Caserta, sparpaglione. Diese Namen beruhen auf einer Verwechslung der Fledermäuse mit grossen Nachtfaltern; beiden gemeinsam ist ja auch die Art des Fluges, der bei der Fledermaus sowohl wie beim Schmetterling kein eigentliches Fliegen, sondern ein Flattern ist. 1

Anderseits: Soriano (Catanzaro), Calasci (Aquila), uccello di notte; womit $\mathrm{zu}$ vergleichen alban. zògou $i$ nátase, "oiseau de la nuit $=$ chauve-souris" 2 und $\zeta o x$ vó $\iota$; $^{3}$ Fano, Cerchiara ecc. (Teramo), 'cellonero; Pietra Camela (Gran Sasso d'Italia), 'cellomérso. Was ist -merso?

Aufserdem werden die Fledermäuse mit bestimmten Vogelarten verglichen oder verwechselt. Nussafia teilt als eine neapolitanische Benennung für Fledermaus facciommo mit. 4 facciommo, facciomme, facciomu, faccid'omu, sfacciommo, sind auch neapolitanische und sicilianische Namen der Nachteule (Strix fammea $L)^{5}$ und passen auf beide: verschiedene Fledermausarten, so gut wie die Nachteule erscheinen als Carricaturen eines menschlichen Angesichts. - Das lat. noctua ist der Name der Eule; nottolo auf der Insel Elba Bezeichnung einer Eulenart (Scops Giu Scop.); ${ }^{\circ}$ die bereits besprochenen nottola, nottolone "Fledermaus" sind aufserdem toscanische Namen eines nächtlichen Vogels, des Ziegenmelkers (Caprimulgus europaeus L). ${ }^{7}$ - In Tempio (Gallura, Sardinien) ist passulitolta (i. e. passero

1 Dies ist auch der Sinn von „Fledermaus“, „eigentlich Flattermaus zu ahd. fledarön, mhd. vlëdern "flattern", (a). Ebenso wird das englische bat als Entstellung von bakke, das für blakke stehen soll, erklärt; isländ. blaka = flattern (b). - Hierher gehört auch poln. latomysz, die flatternde Maus (c) und andere slavische Benennungen, wie die auf die Form perch. (neusloven. prhati flattern) zurückgehenden: kleinruss. perchač, pyrchać, poperchac $\ddot{c}$, potyrcha $\dot{c}$, myšspercha $\check{c}$, Fledermaus; russ. Letučajamyš $\check{s}_{b}$ die "flatternde Maus". Ferner neusloven. pirhpogača (d), pirožlek (,,in pir steckt wahrscheinlich perch.") (e),

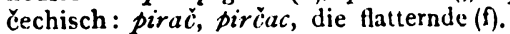

2 Auguste Dozon, Manuel de la langue Chkipe ou Albanaise. Paris 1878.

$3 G$. Stier, Die albanesischen Tiernamen (Kuhn, Zeitschr. für vergl. Sprachforschung Bd. XI 1862 p. 138.

1. c.

5 O. G. Costa, Vocabolario zoologico, s. v. faccidmmo. - De Vincentiis, Vocabolario del Dialetto Tarantino. Taranto 1872 s. v. sfacciommo.

B E. H. Giglioli, Avifauna Italica. Elenco delle specie di uccelli stazionarie o di passaggio in Italia colla loro sinonimia volgare, etc. Firenze 1886 p. $196 . \quad 7$ id. ib. p. 228.

a) F. Kluge, Etymolog. Wörterbuch der deutschen Sprache. 4. Auff. Strassburg 1889 s. v.

b) W. W. Skeat, A concise etymol. Diction. of the English language. Oxford 1882 s. v. $\quad$ c) F. Miklosich, Et. Wörterb. s. v. netopyrí,
d) id, ib. s. v. perch..
e) id. 2 . s. v. pirožleku.

f) id. ib. s. v. pyricì. 
storto $)=$ Fledermaus; nach Spano, 1 passalitolta, nach Marcialis, 2 passarutoltu. Passalitortu; passinitrotta sind sardinische Namen des Ziegenmelkers. ${ }^{3}$ Hier wird wohl auch mit seinem ersten Teile das lecces. passapittula anzureihen sein, während mir -pittula dunkel ist. Fledermäuse sind nächtliche Tiere, wie Eule und Ziegenmelker. Ihnen gemeinsam ist auch der geräuschlose Flug. Darum darf in der Stelle der Odyssee, ${ }^{b}$ wo die abgeschiedenen

\section{$11 . \mathrm{c}$.}

2 Marcialis Dott. Efisio, Piccolo Vocabolario Sardo-Italiano dei principali e più comuni animali della Sardegna. Cagliari 1892.

8 E. H. Giglioli, Avifauna Italica 1886 p. 196.

- A. Bernardini Marzolla, Saggio di un Vocabolario domest. del Dialetto Leccese. Lecce, 1889.

5 Od. XXIV, 5, 9 .

Hierher gehören wohl auch verschiedene slavische, rumänische und albanesische Namen der Fledermaus: serb. ljilak; rumen. lilidc, lilêk; alban. tšorTelek. Das poln. lelek bedeutet Nachteule (a); kleinruss. lel $a k$; russ. lelek ${ }_{b}$; lit. lelis; lett. lêlis, Ziegenmelker (b). Der Vergleich mit den genannten Vögeln liegt näher als der mit dem Storche, der herangezogen wird (serb. lelek, ljiilak, kleinruss. teteka; russ. leklekb; - türk. leklék, léjlék; alban. l'el'ek, l'eil'ek; ngriech. $\lambda \varepsilon \lambda \dot{\varepsilon} x \iota$, Storch (c)), und wahrscheinlich nur durch Volksetymologie mit der Fledermaus in Beziehung gebracht worden ist.

Der erste Teil des albanesischen t'sorl 'el' ek bedeutet „blind“, („,tsór scut. $=$ ḱor, blind (d)); denn bei Tage sieht die Fledermaus schlecht; daher auch altspan. murciego, nspan. murciegalo, portug. morcego, i. e. mus caecus, caeculus (e); bret. lógôden-zall, die blinde Maus (f), Um so besser sieht sie aber bei Nacht, wovon ihr kleinrussischer Name nočovyd, die bei Nacht sehende (g), die dafür am Tage schläft: daher neusloven. mîzkut, fledermaus: die schlafende(h), und spečimiš, die schlafende Maus, Fledermaus (i).

Auch das französische chauve-souris ist nach Grandgagnage's Vermutung, die Diez zufolge Beachtung verdient, eine Umdeutung von choue-souris, Mauseule, „da die wallonischen Formen chawe-sri, chau-sori, chehau-sori auf diese Zusammensetzung führen," und „auch die picard. Formen cas-seuris und cate-seuris sich in cave-seuris, cavette-seuris zerlegen lassen" $(\mathrm{k})$. Zu vergleichen sind auch noch die folgenden bei Bouvier (l): Nord, catesri, Somme, ca seuri, cate seuri, keute sori, Moselle, chaude séri (saute souri, saute sri); Champagne, Poitou, Charente Infér. souri chaude; Bourgogne, chaivon sri; (Berry: chavant, Käuzchen)(m). - Chauve in Chauve-souris mag teilweise durch Volksetymologie aus choue, Eule hervorgegangen sein; beide Benennungen gehen infolge der Klangähnlichkeit der verschiedenen Formen in einander über.

a) Miklosich, Etym. Wrtrb. d. slav. Spr. s. v. lelekū.

b) id. s. v. Leljakis.

c) id. s. v. lelekü cf. d).

d) Gust. Meyer, Etymologisches Wörterbuch der albanesischen Sprache. Strassburg 1889. s. v. l'el'ek.

e) Diez, Et. W. d. rom. Spr.

f) Le Gonidec, Dictionnaire français-breton ed. Th. Hersart de la Villemarqué. 1847 s. v. chauve-souris.
g) Miklosich, 1. c. s. v. vid-.
h) id. ib. s. v. mì gr.

i) id. ib. S. v. süp-.

k) Diez, l. c. s. v. chauve-souris.

1) A. Bouvier, Les Mammifères de la France. Etude générale de toutes nos espèces considérées au point de vue utilitaire. Paris 1891 p. 3.

m) Dies. E. W. II c. S. v. choe. 
Seelen der Freier mit Fledermäusen verglichen sind, $\tau \rho(\zeta \varepsilon \iota \nu$ nicht mit "schwirren" übersetzt werden; die Bedeutung ist, wie in der Ilias, wo von jungen Vögeln die Rede ist, 1 ,zirpen“. Wer je in einer Höhle einen Schwarm aufgescheuchter Fledermäuse beobachtet hat, weils, dafs dieselben einen zirpenden Ton vernehmen lassen. Wir dürfen der genauen Naturbeobachtung eines Homer zutrauen, dafs ihm dies nicht entgangen war.

Ein zweiter Name der Fledermaus in Tempio (Sard.) ist babbarottu; Ins. Maddalena, papparotto; Taverna (nordöstl. Sardinien), pipparottu. Nach Spano ${ }^{2}$ ist babbarrottu, nach Giglioli ${ }^{3}$ paparottu sardischer Name einer Schwalbengattung, des rondone (Cypselus apus L). Wir kommen auf dieses Wort zurück.

In Arena di Calabria u. s. w. (Pr. Catanzaro) heifst die Fledermaus lindanella de notte; in Palizzi (Reggio Cal.), rindaneddi di notte (pl.), in Condofuri (Reggio Cal.) einfach rindara, rindineda. Lindanella, rindara u. s. f. ist der Name der Schwalbe, rondine (Hirundo).

In Sàssari (Sard.): zir rióla (Spano 4 hat zirriollu); Bonorva (Sard.), zirriólu pedde (Spano: tirriolu pedde, ${ }^{5}$ Ferraro: 0 Chiaramonti (Log.), tirriolu-pedde, zirriolupedde.) Zirriolu ist aufserdem ein sardischer Vogelname, nach Spano ' "occhione, calidra"; siriolu, Wasservogel, Hjaticula. ${ }^{8}$ Ebenso gibt Giglioli ziriolu als sardinischen Namen des Oedicnemus scolopax Gmel. (occhione), ${ }^{9}$ und des Aegialitis Hiaticula, 10 sowie zurruliu als sardisches Synonym dieses letzteren, 11 der calidra (Calidris Arenaria L), ${ }^{12}$ des Machetes pugnax $L, 13$ des Tringoides hypoleucus $L .,{ }^{14}$ des Totanus nebularius Gunn. ${ }^{15}$ u. s. w.

In Thiesi und Mores (Sard.) fand ich als Fledermausnamen cinciriolu; in Fonni und Umgegend, cincimurru; in Samassi (Sard.), sitzimureddu (bei Spano: logudor: sinzimureddu). ${ }^{16}$ Mit diesen Benennungen sind zu vergleichen: cincirri, it. zigolo, eine Vogelart; ${ }^{17}$ cincirri a dentes, it. strilozzo, eine andere Vogelart. 18 Zisi, zinsia sind ferner sardische Namen des "zigolo nero" (Emberiza cirlus L); zisi heifst derselbe auch im Piemont, zizi im District von Rovereto; ${ }^{19}$ zinzi heifst in Genua der "beccamoschino" (Cisticola cursitans Frankl.) ${ }^{20}$ All diese Benennungen, soweit sie sich auf Vögel beziehen, scheinen

$1 \mathrm{II}, \mathrm{II}, 3,14$.

8 Giov. Spano, Vocab. Sardo-ital. s. v. babbarrottu.

31 c. p. 193.

1. c. 5 Vocab. Ital-sardo II. s. v. pipistrello. ${ }^{6}$ Gius. Ferraro, Canti popolari in Dialetto logudorese. P. I. Torino 1891. 7 Vocab. Sardo-Ital. s. v. zirridlu. ${ }^{8}$ id. ib. s. v. ziriolu. 8 l. c. p. 367.10 l. c. p. 374.11 id. ib. 12 1. c. p. $390 .{ }^{13} 1$. c. p. 391 .

14 1. c. p. 393. Vgl. auch: Eug. Rolland, Faune populaire de la France. Les Mammiferes sauvages. Paris, 1877 p. 3.4.

15 Vocab. Sardo-Ital.

16 Spano, Vocab. Sardo-Ital.

17 id. ib. s. v. cincirri. ${ }^{18}$ id. 2 b. cf. Giglioli, 1. c. p. 46.47 : cincirri a dentes, it. strilozzo (Miliaria Projer Müll).

19 Giglioli, 1. c. p. 48. $49.2^{20}$ id. ib. p. 141 . 
Onomatopoeien. $1 \mathrm{Da}$ übrigens auch die Fledermäuse einen zirpenden, übrigens nicht immer sehr angenehm klingenden Ton vernehmen lassen, so mögen manche der vorstehenden Bezeichnungen direkt auf die Fledermäuse angewandt worden sein, unabhängig von einer Übertragung der Vogelnamen.

Das wäre ein e Erklärung für die erwähnten Zusammensetzungen mit cinci-, zinzi-. Andere Zusammensetzungen weisen dagegen auf eine viel allgemeinere Bedeutung derselben. So fand ich in Fonni neben cincimurru, Fledermaus; cincigorru, Schnecke (Cagliari, sizzigorru) ; cincilugu, Leuchtkäfer. Ferner: Planargia, zinzigorru; Gebiet von Nuoro, zinzimurreddu, Cerambix (der "gehörnte“ Käfer). ${ }^{2}$ Sulcis, sisigraxia; Sinnai, sizzigolla, Cicala. ${ }^{3}$ Überblickt man alle diese Tiernamen, so können, wie mir scheint, cinzi-, sinzi-, sisi-, sizzi- wohl kaum anders denn als Deminutiva aufzufassen sein; man vergl. bei Spano,4 cicciu, "cucco", cicciubedddu, „trastullo". Ein Deminutiv als Anlaut ist aber baskisch; die baskischen Tiernamen chinchinbare, chinchinmare, Blutegel; chinduri, chinguri, chinhaurri, Ameise; chichari, zizari, Wurm, ${ }^{5}$ könnten dem Klange nach ebensowohl sardische Wörter sein. Zu vergleichen ist auch bei van Eys ${ }^{6}$ s. v. che, ch, chiki. Dann wären aber ebenfalls als wenigstens in ihrem ersten Teil iberisch ${ }^{7}$ hierherzuziehen die liparischen Benennungen der Fledermaus, izirizi, izidiri $i^{i} ;{ }^{8}$ sowie die bereits besprochenen sardischen Namen für Fledermaus, zunzuritos, zurrundeddu, zurundelli gleichfalls iberischen Ursprung haben dürften: bask. chori, „oiseau, généralement pour les petits oiseaux". 9

Ebenso haben tirriolu und zirriolu eine weit allgemeinere Bedeutung. Spano ${ }^{10}$ gibt für ersteres vor Allem „bestiola“ an, und tirridlu pedde als Namen eines Käfers („Prionus coriarius“); so wie auch Marcialis 11 zirriolu von Ozieri als Bezeichnung eines Käfers (Cerambix) erwähnt.

Eine kleine Gruppe zusammengehöriger Namen der Fledermaus aus den Gebieten von Sondrio, Bergamo, Brescia, Mantova, Verona, Venezia u. s.f. ist hier zu erwähnen wegen des zweiten Teiles des zusammengesetzten Wortes. Sondrio (Veltlin), grignöpiila; grignopula. 12 Berg. und angrenzendes Gebiet von Mailand, sgri-

1 In der Lunigiana deuten die Kinder, die, wie anderswo, vogelsprachekund, aber zugleich realistisch sind, den Gesang des Oriolo (Oriolus Galbula L) wie folgt:

2 Marcialis, s. v.

la ciriegia a mangiare son buone

ma a c.... i nocchioli, giuradio!"

4 Voc. sardo-it. s. v.

5 W. F. van Eys, Dictionnaire basque-français. Paris-Londres 1873 . s. v.

6 1. c. 7 Vgl. übrigens Diez, E. W. I s. cica.

8 Mündliche Mitteilung von Prof. Giglioli.

9 van Eys, s. v. 10 1. c. s. v. 11 l. c. s. v.

18 R. Bruno Galli Valerio, Materiali per la Fauna dei Vertebrati Valtellinesi. Sondrio 1890 . 
gnápola;1 bresc. sgrignápol, grigndpola, ${ }^{2}$ gregnapola; 3 cremasco, grignápola, sgregnapola $; 4$ veron., zigndpola; ${ }^{5}$ veron. ven., zignapola ; ${ }^{6}$ mant. gregnappola, sgargnápola ${ }^{7}$ cremon., greugnapapoula ${ }^{8}$ gregnapápola. ${ }^{9}$ - Daran schliefsen sich an im Gebiet von Nicastro (Catanzaro), coniripola; in Tirriolo (Catanzaro), curinipula. ${ }^{10}$ pola ist in bergamarkischer Mundart der Name der Schnepfe, 11 Scolopax Rusticula L.12 Den gleichen Namen führt im Venezianischen und in Terranova (Sicilien) ein anderer Vogel, der Lycos Monedula, ${ }^{13}$ und in der Provinz Belluno der Fregilus graculus. ${ }^{14}$ pola halte ich für das latein. pullus; (ngriech. $\pi 0 v \lambda i o v$, Vogel). Was den ersten Teil der oberitalienischen Namen betrifft so sagt darüber Mussafia: „cremon. grögn., mit sgrignare, höhnisch lächeln zusammenhängend." 15 sgrignápola und seine Sippe wäre demnach "grinsender Vogel". Thatsache ist, dals viele Fledermäuse einen grinsenden Gesichtsausdruck zu haben scheinen, womit zu vergleichen, was oben bei Gelegenheit von facciommo bemerkt wurde, sowie franz. chat-huant (,höhnende Katze") und huant, beides Namen der Eule. 16 Bol., sghergnapapla; romagn., sgregnapdpol, sgregnapdpula; ven. sgrignapapoli; ferr. sghignapule, haben die Bedeutung "ridone", Lachhans; parm. sgargnaplapla, „donna che sghignazza", 17 wobei man fragen kann, ob dies eine Übertragung vom Namen der Fledermaus ist, oder umgekehrt. - Eine andere Deutung gibt Flechia: "... casipola, casupula presenterebbe piuttosto per noi un suffisso sporadico, formativo di diminutivi o spregiativi, quali s'incontrano quà e là ... in alcuni dialetti, massime dell' alta Italia." Als Beispiele werden angeführt: „manopola" „quasi manaccia, mano falsa"; piem. vinapola "vinello"; verb. vissopola (= bisciopola) „lucertola“, berg. sgrignapola, mant. sgargnapola „pipi-

1 Cherubini, Vocab. Mil.-Ital. Milano 1839-1856. - Tiraboschi, Vocabol. dei Dialetti bergamaschi antichi e moderni. 2a ed. Bergamo 1873. - Biondelli, Saggio sui dialetti Gallo-Italici. Milano 1853.

\& Biondelli, 1. c. - G. Rosa, Vocab. Bresc.-Ital. delle sole voci che si scostano fra loro. Brescia 1878 .

3 Vocabol. Bresciano e toscano. Brescia 1759. - Rosa, 1. c.

- Bonif. Samarani, Vocab. Cremasco-Ital. Crema 1852.

B Angeli, Piccolo Vocab. Veronese e toscano. Verona 1821. - Biondelli 1. c. ${ }^{\circ}$ Angeli, 1. c. - Ninni, 1. c.

I F, Cherubini, Vocab. Mantov.-Ital. Milano 1827.

8 A. Peri, Vocabolario cremonese-ital. Cremona 1847.

- Biondelli, l. c. - Mussafia, l. c.

10 O. G. Costa, Vocabolario zoologico. p. 49 s. v.

11 Tiraboschi, l. c.

12 E. H. Giglioli, Primo Resoconto dei Risultati della inchiesta ornitologica in Italia. Parte I. A vifauna Italica. Firenze 1889, p. 609.

${ }_{18}$ Giglioli, Avifauna Italica etc. Firenze 1886 p. 12. - id., Primo Resoconto u. s. f. Firenze 1889 p. 32

14 Giglioli, Avifauna Italica, 1886 p. 16.

15 1. c. p. 32 s. v. barbastrello.

16 Diez, 1. c. II c s. v. choe.

17 Vgl. die Wörterbücher von Ferrari, Coronedi-Berti, Aureli; Mattioli; Boerio; Nannini; Peschieri. 
strello", e var. com. grignapol "chi ride, grigna, per niente", u.s.w. 1 - Die Bedeutung von coniri-, curini- in den beiden calabresischen Namen ist mir ganz dunkel.

Eine genauere Beobachtung der Fledermäuse führte und führt zur Unterscheidung von den Vögeln; sie werden den Säugetieren angenähert und erscheinen nun zunächst dem Volke als Zwittergeschöpfe zwischen Mäusen (Ratten) und Vögeln. Also:

Nicotera (Calabr.), sorici occegli (pl.); ital. Tyrol, losell sores; pav., uselratt ${ }^{2}$ vielleicht auch hierher gehörig: Oneglia (Ligurien), rattasuia; Corte (Corsica), accelu topinu, uccello tupino; Vaglisotto (Massa), top'uccello; Tagliole (Alto Frignano, Modena), mezzotop' e mezz'uccello; S. Terenzo (s/M Ligurien), mezzoratto e mezz'uccello; churw., mez mür e mez uce, ${ }^{3}$ miez mieur a miez utschi ${ }^{4}$ Obwald. (Raetorom.) ${ }^{5}$ mięts miur mięts utši; Unterengad. ${ }^{6}$, utšemetsmv́r; Oberengad., ${ }^{7}$ vtšemetsmkv́r; Marcellinara (Prov. Catanzaro, Calabr.), 8 sùrice mienzu ocieddu; Lago Maggiore, mezzaratt; Paves. und Lago Maggiore mezzarat, ${ }^{9}$ mezzaratta. ${ }^{10}$ Das comask. muserat, museratt, 11 ist vielleicht nur Entstellung vom vorigen, vielleicht aber auch zu deuten als "muso di ratto" d. i. Mäuseschnautze. Fano Adriano (Teramo), mezzo surgi. An dieser Stelle sind auch die schon erwähnten sardischen Namen cincimurru, sitzimureddu (zinzimureddu) nochmals aufzuführen, in deren zweitem Teil mit Mussafia 12 das lat. murem zu sehen ist. Wie sazza- in sazzamureddu (Decimo Mannu, Sard.) zu deuten ist, weirs ich nicht zu sagen, es findet sich wieder in sazzaluga, dem sardischen Namen eines Reptils, Gongylus ocellatus. Vgl. übrigens unten sacca-pinnuto.

Endlich wird der Begriff „Vogel" ganz aufgegeben: Ins. Ponza, nach Mitteilung von Prof. Giglioli: soricilli di notte; Tre Pievi (Comasco), ${ }^{13}$ golanbcc; Oberhalbst.(Raetorom.), ${ }^{14}$ żgulanót $\chi$;Piacenza, ${ }^{15}$ ratt barbastell; San Fiorenze (Corsica), topo menudo (kleine Maus?; siehe auch weiter unten); Foggia, scurchiggione, ${ }^{16}$ spurtagghione; 17 Gessopalena (Chieti), 18 scurpénge; Assergi (Aquila), scurpiccieri. Letztere vier aus sórice, suirice, surge, Maus entstellt, oder zu spor-

2 A. G. I. IV. 1878 p. 380.

2 Mussafia, l. c. 3 Mussafia, 1. c.

- Mathias Conradi, Taschenwörterbuch der Deutsch-Romanischen Sprache.

Zürich 1828. s. v. Fledermaus.

s Gartner, Die raetoroman. Mundarten 1. c.

6 id. ib. 7 id. 20.

8 Franc. Scerbo, Sul Dialetto Calabro. Firenze 1886.

- B. Biondelli, Dial. Gallo-Ital. - Mussafia, 1. c.

10 Cherubini, Vocab. Milan.-Ital.

11 P. Monti, Vocab. dei Dial. di Como s. v. mesaràt, Mussafia, 1. c.

12 1. c. p. 32 Anm. 2.

18 P. Monti, Vocab. dei Dial. di Como.

14 Gartner, 1. c.

15 Lor. Foresti, Vocab. Piacentino-Italiano. IIIa Ed. Piacenza 1883. s. v.

16 Briefliche Mitteilung von Prof. Giov. Peruzzi in Terni.

17 Brief. Mitteilung von Prof. Luigi Bordi in Foggia.

18 Genn. Finamore, Vocab. dell'uso abruzzese. Lanciano 1880. 
tigliuin? Savona (Ligurien), rattarattoeia. Als Aehnlichkeit mit Vögeln bleiben nur die Flügel; die Fledermäuse werden zu fliegenden, geflügelten Mäusen oder Ratten:

Cremasco., gularat ( $\mathrm{g}$ für $\mathrm{v}$ in volare1); Lomb. ratt sgolavd; 2 Lodig. und angrenz. Lomb. ${ }^{3}$ ratt-sgolado; Lago Magg., rattavol; Pavese 4 , rattavola, rattavóla; Piazza Armerina (Sicilien) ${ }^{5}$ ratavola, rattavola; Gergo Valsoan. ${ }^{6}$ rattavóla (vgl. Jouxtens b. Lausanne, ${ }^{7}$ rattavol); Pavese, ratävolä, 8 ratavoula; ${ }^{9}$ Piazza Armerina (Sic.), 10 ratavuledda; Arona, ratavolï; Vercelli (Piem.), ratavulíra; Carpeneto (Alto Monferrato), 11 ratardura, (raura für aura = aria?) Acqui (Monferr.), 12 rattaraula (Vergl. Prov. ratairol, 13 als Deminutiv aufgefalst, mit der Deutung „petit rat, taupe“; vielleicht doch eher als „Fledermaus“ zu deuten, die auch für blind gilt.); Casale Monferr. und Piem. rata vulojra; 14 Piem. rata voloira, ${ }^{15}$ ratavouldjra, rat vouloùr; ${ }^{16}$ Val Soana, ${ }^{17}$ ratavolojri; Canavese, 18 ratavolä'ra; Pral (Valdenser im Piemont), 19 rātov'lujro; [cf. Orbe (Vaud), rata volaire, „Rom. Schweiz“, 20 rattavolaire; Rumilly (Savoien) und Wallis, ${ }^{21}$ rate-voliere; Roman. Schweiz, ${ }^{22}$ ratouliva, ratta-volia; Savoien (link. Ufer des Genfer See's), und Genf, 23 ratüliva, ratoulive, ratolive (Zusammenziehung von ratevolive); Jura (Schweiz), ${ }^{24}$ ratevolate; Vosges, ${ }^{25}$ volant-rette; in manchen Gegenden Spaniens, ${ }^{26}$ raton volante; Ain (Frankr.), ${ }^{27}$ ratta voulesse, ratta

1 Samarani, l. c. s v. 2 Cherubini, Vocab. Milan.-Ital, s. v.

8 Biondelli, Saggio sui Dial. Gallo-Ital. s. v. - Cherubini, 1. c. Mussafia, 1. c.

Biondelli, 1. c. - Cherubini, 1. c. Vol. V. Agg. o corr. s. v. messardtt.

- Remigio Roccella, Vocabolario della Lingua parlata in Piazza Armerina (Sicilia). Caltagirone 1875. s. v.

- C. Nigra, Fonetica del dial. di Val-Soana (Canavese). A. G. I. III. 1878. Appendice p. 43 Anm. 2.

7 Briefl. Mitteilung von Herrn Alfred de Rham in Jouxtens b. Lausanne.

8 Diz. dom. pavese-ital. P. I. Pavia, 1829. s. v.

- Rod. Manfredi, Diz. Pavese-Ital. Pavia 1874. 10 Roccella, 1. c.

11 Gius. Ferraro, Glossario Monferrino. IIa Ediz. Torino 1889. s. v.

12 id. ib. 'ts Raynouard, Lexique Romand ou Dictionnaire de la langue des Troubadours, Paris, $1838-1844$, s. v.:

Cant eu la vei, tot m'abelluc, et oclei mai d'un ratairol. (Un troubadour anomyme: Can vei).

("quand je la vois, je suis tout ébloui, et je suis aveugle plus qu'une taupe“.)

14 Gius. Ferraro, 1. c. is Vittorio di Sant'Albino, Gran Dizion.

Piemontese-Ital. Torino 1859. s. v. - Michele Ponza, Vocab. Piemontese-

Ital. Torino $1830-33$. s. v.

16 Maggiore Dal Pozzo, Glossario Etimologico Piemontese. Torino 1888. s. v. ratavouldjra. ${ }^{17}$ C. Nigra, 1. c. 18 id. ib.

19 G. Morosi, L'odierno linguaggio dei Valdesi in Piemonte (A. G. I. XI. 1890. I. Dialetto di Pral. p. $330-367$ ).

${ }^{20}$ Doyen Bridel, Glossaire du Patois de la Suisse Romande. Lausanne 1866. (Mém. et Documents publiés par la Société d'Histoire de la Suisse Romande, T. XXI).

21 fean Humbert, Nouv. Glossaire Genevois. Genève 1852 .s. v. ratoulive.

22 Humbert, 1. c. - Bridel, 1. c. 93 Humbert, 1. c.

24 id. ib. $\quad{ }_{25} i d . i b$. cf. Ascoli, Schizzi franco-provenzali (A. G. I. III, 1878 p. 115).

so Nemnich, Allgemeines Polyglotten-Lexicon der Naturgeschichte. Hamburg und Leipzig 1793. 27 A. Bouvier, 1. c. p. 3. 
volante; Saône et Loire, 1 ratte volerate, rate voluche, rate voluce; Lyon, rata volagi, 2 rate volage. ${ }^{3}$ ]

Perfugas (Sassari, Sard.), sórighe pinnádulu (Spano, Nördl. Sard.: sorighe pinnadule; (cf. prov. sorits penada ); Leccese, surge ulateu; 5 Carignano (Piemont), giari-volan; Bastia (Corsica), topo pinnuto; Calvi (Corsica), sacca-pinnuto. (Bask. sagu ist "souris“ (van Eys, Dictionn. basque-français. Paris-Londres 1873). Bei diesem Anlars ist auch auf das corsische jacaru, „uno dei nomi del cane" aufmerksam zu machen, ${ }^{6}$ womit zu vergleichen bask. zakur, chakur, zakhur, bei van Eys (Dict. b.-fr.); S. Fiorenze (Corsica), topo menudo (menudo Entstellung von pinnuto?); Cagliari (Sard.), ratta pignátta; Südl. Sardinien, Alghero, ${ }^{7}$ arratapigndla; Alghero (Sard.), ratta pignára, rattapignara, ${ }^{8}$ ratapiñara, ${ }^{9}$ (cf. Pyrén.-Orient.10 rata panera), rata piñada 11 (ebenso Catalon.; cf. prov. 12 ratapennada, ratapenada; Tarn, 13 rato penado; Languedoc, 14 rata penada, rato penado; Cantal, Haute-Loire 15 rata peinada; Gard 16 rato panado); Genov., ratto pennügo, ${ }^{17}$ rattopennûgo, ratto-pennûgo, ${ }^{18}$ ratto penûgo, ${ }^{19}$ rattupenügu; ${ }^{20}$ Carloforte (Sard.), 21 rattu spenugu; Santa Margherita Ligure, 22 ratto pernugo (cf. Tarn, 23 rato perno); Bonifazio (Corsica), ${ }^{24}$ ratti pendïi (plur.); Porto Venere (Ligur.), ratti pennüi (plur.); Cernobbio

1 id. $i b$.

2 Onofrio, Glossaire lyonnais, p. 368. cf. Diez (trad. Bauer), Anciens Glossaires Romans. Paris 1870, p. 47.

8 Humbert, 1. c.

- Raynouard, 1. c. s. v.

- G. Morosi, Il Vocalismo del Dialetto Leccese (A. G. I. IV, 1878. p. $117--144$ s. v.

- Falcucci in Papanti, I Parlari Italiani in Certaldo. Livorno 1875. p. 573.

- Spano, Vocab. Sardo-ital. s. v.

8 Marcialis, Picc. Vocabol. Sardo-ital. dei principali e più comuni animali della Sardegna. Cagliari 1892. s. v.

- P. E. Guarnerio, Il Dialetto Catalano d'Alghero. (A. G. I. XI. 1885 p. $261-363$. 10 Bouvier, 1. c.

11 G. Morosi, L'odierno Dialetto Catalano di Alghero in Sardegna.

In Memoria di Napoleone Caix e Ugo Angelo Canello. Miscellanea di Filologia e Linguistica. Firenze 1886. p. 313-332.

18 Raynouard, l. c. s. v.

18 Bouvier, 1. c. 14 id. ib. 15 id. ib.

16 F. Crespon, Faune méridionale. Nimes, Montpellier, 1844 , in Eug. Rolland, Fauna populaire de la France. Les Mammifères sauvages. Paris I877. p. 1 .

${ }_{17}$ P. Angelo Paganini, Vocabol. dom. Genovese-Italiano con un Apperdice zoologico. Genova 1857.

18 Giov. Casaccia, Dizion. Genov.-Ital. Sec. Ediz. Genova 1876. s. v.

19 Paganini, 1. c. 20 Gius Olivieri, Dizion. Genovese-Italiano. Genova I851. 21 Marcialis, 1. c. s. v.

22 Mündl. Mitteilung von Prof. Guelfo Cavanna in Florenz.

28 Bouvier, 1. c. - Rolland, 1. c. p. 3 führt rato perno nach Couzinié (Dictionnaire de la langue romano-castraise et des contrées limitrophes) an, und gibt folgende Deutung: "perno = planam, par métathèse et changement de 1 en r." perno ist doch wohl eher Entstellung aus penno, penne, vergl. weiter unten ratapene, rat penna u. s. w.

24 Mündliche Mitteilung von Prof. Giglioli in Florenz. 
(Lago di Como), rattpignöl; Liguria, 1 ratapene; (cf. franz. Jura, 2 Dauphiné, ${ }^{3}$ rata pena ; Lyonnais, 4 rate penne; Valenza (Span.), ${ }^{5}$ rat pennat; Prov., 6 rata-penau).

Wie man sieht, finden sich diese Zusammensetzungen - einerseits mit dem vermutlich celtischen ratta, anderseits mit den mehr oder weniger entstellten lat. pinnatus, pennatus - in Ligurien, von der toscanischen Grenze an, in Piemont, Savoien, der Provence, und erstrecken sich nördlich bis über Lyon hinaus, in die romanische Schweiz und die Vogesen; südlich nach Spanien. In die Inseln Corsica und Sardinien sind sie aus Ligurien und Spanien eingedrungen. Isoliert in Unteritalien findet sich das lecces. gattupignula, ${ }^{7}$ das fast wie eine Importation aus Oberitalien erscheint. gattu- mag eine wenig glückliche Umdeutung des im Süden nicht verständlichen ratto, ratta sein. Sodann Neapel: sparapingolo, ${ }^{8}$ sparrpignolo ${ }^{9}$ Castiglione a Casauria (Abruzzen), 10 sparapinge; Isola del Gran Sasso (Teramo) mastripengi; Pr. Chieti, sopreppenguele; in deren zweitem Teile wohl das Thema penna, pinna enthalten ist, während ich für spara-, sparr-, sopre-, masiri- keine Deutung wage.

Das deutsche fledermaus hat sich in Asiago (Sette Comuni, Vicenza) als fudermaus erhalten, sowie in den XIII Comuni des Veronesischen, wo noch $\mathrm{i} ; 63$ fiedermaus gesagt wurde, als fiddemaus; $" 1$ in den deutschen Gemeinden des Piemont als fladermus, pl. fladermis. 12 Vergl. grödn. Alidermaus; 13 lusern. floddermaus, fluddermaus. 14

Weiterhin greift die Phantasie des Volkes zu andern wirklichen oder angeblichen Eigenschaften des Tieres. Es wurde bereits aus Sardinien (Bonorva) zirriolu pedde erwähnt, d. i. Vogel mit Fell, Haut (statt der Federn). Andere sardische Namen besagen einfach : Hautflügel, Fellfügel:

Bosa (Sard.), alibedde; 15 Fonni (Sard.), ala de pedde; Goceano (Sard.), alipedde; ${ }^{16}$ Sárula, Fonni (Sard.), alipedde; Desule (Sard.), ali e vedde; Villagrande (Sard.), alas de vedde; Terranova (Sard.), ala

1 Gius. Ferraro, Glossario Monferrino.

2 Bouvier, 1. c. \& Rolland, 1. c. p. 3.

- Rolland, l. c. 5 Nemnich. 1. c.

- Honnorat, Dict. Provençal-français, Digne. 1846. 1847.

2 Gius. Costa, Fauna Salentina.

8 O. G. Costa, Fauna del Regno di Napoli, p. 5.

- M. Lessona, Storia natur. illustr. dei Mammiferi.

10 Genn. Finamore, 1. c.

11 Vocabolario di don Marco P'ezzo, Verona 1763. Siehe Francesco e Carlo Cipolla, Dei Coloni Tedeschi nei XIII Comuni Veronesi (Archivio Glottol. Italiano VIII 1882 p. 151 ). Der Vollständigkeit halber ist hier nachzutragen, dafs sard. zirriolu u.s. f. auch an arab. their el-hil Fledermaus anklingt.

12 Giov. Giordani, La Colonia tedesca di Alagna-Valsesia e il suo dialetto. Opera postuma. Torino 1891.

${ }_{13}$ Th. Gartner, Die raetorom. Mundarten. 1. c. p. 470.

14 F. v. Zingerle, Lusernisches Wörterbuch. Innsbruck 1869.

15 Spano, Voc. Sardo-Ital. s. v. 16 id. ib. s. v. 
e peddes; Bosa (Sard.), attilipedde; Olzai (Sardin.), sunzumurreddu alipedde; 1 Mussafia fragt, ${ }^{2}$ ob sard. "alibedde", Fledermaus, nicht als "schöne Flügel" zu deuten ist. Aber in Sardinien habe ich in den erwähnten Namen immer nur pedde und vedde gehört, und pedde ist Haut, Fell. Mussafia's Vermutung ist auch aus sachlichen Gründen abzulehnen, da es Niemandem, aufser etwa einem Naturforscher, in den Sinn kommen wird die Fledermausflügel schön zu nennen. ala de pedde und seine Sippe entspricht dem griechischen Adjectiv $\delta \varepsilon \rho \mu о ́ \pi \tau \varepsilon \rho \circ$, welches Aristoteles und Aelianus mit Bezug auf die Fledermausflügel anwenden. Ein Sanscritname des Tieres ist ajinapatra "patra aile, mot à mot la bête aux ailes de peau, la chauve-souris". 3

Das merkwürdige arturighiula, arturigghiula aus der Prov. Lecce (Terra d'Otranto) füge ich hier an, weil es an das alban. 'lakurik, l'akurekes Fledermaus ${ }^{5}$ anklingt; was mir aller Beachtung wert scheint, da sich das Wort aut dem Boden des alten Messapien findet. Alban. 'akur, lakurik' ist "nackt" und l'akurik ausserdem

1 Marcialis, l. c. s. v. 2 l. c.

3 Burnouf, Dictionn. class. Sanscrit. Ein anderer Sanscritname ist karmapatrā (mit Lederflügeln), nach Pott (Über Mannigfaltigkeit des sprachlichen Ausdrucks nach Laut und Begriff, in Zeitschr. f. Völkerpsychologie und Sprachwissenschaft. 1860 p. 345). - Gleiche Bedeutung hat norweg. skind-vaenge (a) und breton. askel-groc'hen (b). Vergl. auch isländ. Letr-blaka der "Lederflatterer", Fledermaus (c), und leðr-mus (d); schwed. läderlapp (e); dalek. ledr (f). - Altsloven. koža ist Haut, kožu $h_{b}$, Pelz; kleinruss. und weissruss. koža, kožuch, kožan, Fledermaus (g). Ferner bei Pott (1. c.) ungar., bör-eger (Ledermaus); lettisch, pell-ahda (Fellmaus); lit. sziksnosparnis (Lederflügler).

- O. G. Costa, Fauna del Regno di Napoli, p. 5. - id. Vocabolario zoologico s. v. - Gius. Costa, Fauna Salentina p. II. - G. Costa bezeichnet das Wort als eine der gebräuchlichsten Benennungen der Terra d'Otranto für -die Fledermaus, und gibt davon folgende Etymologie: „La . . . voce ha dovuto alcerto trarre sua origine dal greco idioma - verbo $\alpha \rho \tau \dot{\alpha} \omega$ per indicare il sospendersi, appendere, rimaner sospeso; e l'aoristo $2 \omega^{\prime} \rho v \xi o v$ del

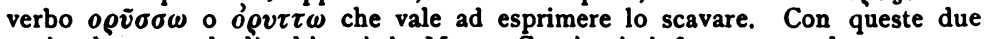
voci adunque, dagli abitanti la Magna Grecia si è formato quel nome per alludere al costume di questi animali, di tenersi sospesi col capo in giù ne' sotteranei e nelle fenditure de' vecchi muri, e simili." Mir scheint, dass man in arturigghiula höchstens das Verbum ó schon Stier (h) den äussern Anklang des alban. l'akurtk', Fledermaus an hamurtk, Maulwurf (ngr. $\chi \alpha \mu \omega^{\prime} \rho v \gamma \alpha \varsigma$ ) als auffallend bezeichnet. "Sodass man zu deuten versucht sein könnte: die Fledermaus vergräbt sich in Gruben, Löcher ( $\lambda \dot{\alpha} \times x$ S $_{\text {, }}$ Graben, Grube) wie der Maulwurf unter die Erde." Dann wäre aber unverständlich, wie l'akurizk zu der Bedeutung "nackt" und "Schnecke ohne Haus", Nacktschnecke, kommt.

6 Gustav Meyer, Etymol. Wörterbuch der albanesischen Sprache. Strassburg 189 I s. s. Pakur.

a) Nemnich 1. c.

b) Le Gonidec, Dict. franç.-breton ed. Th. Hersant de la Villemarqué: "Askel - aile d'oiseau et de quelques insectes. askel-groc'hen chauve-souris signifie à la lettre: aile de peau."
c) Skeat, 1. c.; s. v. bat.
d) Nemnich, l. c.
e) $i d$. $i b$.

f) id. ib. g) Miklosich, Et. W. s. v. koža.

h) Alban. Tiernamen l. c. p. 138. 


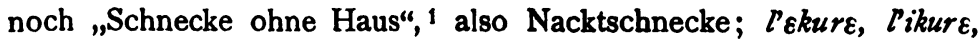
scut., rkur f., Haut, Fell, Leder; Baumrinde. 2

Ihrer Bedeutung nach schliessen sich wohl auch eine kleine Gruppe lombardischer Benennungen am besten hier an:

Lombardei, ralt-tignöl, tegnöra; Mailand (Stadt), tegnöla; Gebiet von Mailand, tegna; ${ }^{3}$ Como, taragnöla; Lecco, tignöl; Lago Maggiore, lomb. Ufer, tagnöl; Esino (Lomb.), tegnaröl, tegnaröla; Varenna, tegnöl.

Das Volk der Lombardei erklärt diese Namen wie folgt: wenn zufällig der Fledermauskot einem Menschen auf den Kopf gerate, erzeuge er daselbst die tigna, d. i. eine Art Grind. Einen ähnlichen Aberglauben erwähnt Rolland 4 aus dem Elsals. Da die "tigna" das Ausfallen der Haare zur Folge hat, so entsprechen meiner Ansicht nach diese Namen dem französischen chauve-souris (calva sorex), 5 und wollen den Mangel der Federn bei dem für einen Vogel gehaltenen Tiere, oder auch den beinahe vollständigen Mangel der Haare auf den Flügeln bezeichnen. 6 In verschiedenen Gegenden Italiens tragen kahle, unfruchtbare Hügel und Berge den Namen Montetignoso. -

Wir haben bereits die sardischen babbarottu, papparottu, pipparotti in der Bedeutung "Schwalbe (rondone)" und „Fledermaus" kennen gelernt. babbarrottu hat in Sardinien ferner den Sinn von „Kinderschreck"; pappurutu findet sich in der gleichen Bedeutung "spauracchio dei bambini" in Calabria Citeriore. ${ }^{8}$ Die nächtliche, ein geheimnisvolles Dasein führende Fledermaus hat ihren Platz in der Mythologie und im Aberglauben. Darum in Cagliari (Sard.), pilloni de su tiaulu,9 d. i. Teufelsvogel. Homer vergleicht die Seelen der Freier mit Fledermäusen (Odyss. XXIV, 5-9).

I Stier, Albanes. Tiernamen, 1. c. p. 138. - G. Meyer, 1. c.

2 G. Meyer, l. c.

3 Mussafia, l. c.

- E. Rolland, l. c. p. 7.

5 Diez, Anciens Glossaires Romans, trad. Bauer. Paris 1870. „Glosses interprétant le texte biblique 192 : vespertiliones calves sorices.“ p. 47 : „vespertilio "calva suricis". Hierher gehört Horning zu Folge (diese Zeitschr. 1890. $\mathrm{XIV}$ p. $22 \mathrm{I}$ ) auch das lyon. rataplana [vgl. Isère, rate plane, rate plaine bei Rolland (1. c.) und Bouvier (1. c.), Castres, (Couzinié b. Rolland 1. c. p. 3, ruto pleno)], was nicht "souris qui plane“ ist, sondern "plana ist hier feminin von plan und bedeutet ,uni, lisse, chauve". So auch schon Rolland (l. c. p. 3).

o In der Mundart von Dax und Umgegend (Gascogne) heisst die Fleder. maus sourits-escaouye, mit Bezug worauf Herr $\mathbf{A}$. Lartigue von Dax, dem ich den Namen verdanke, mir Folgendes mitteilt: „Escaouye est une maladie cutanée qui frappe certains animaux et leur fait perdre le poil. D'où une calvitie. Le mot gascon de cet animal est en français, mot pour mot: souriscalvitie, c'est à dire atteinte de calvitie."

7 Giov. Spano, Vocabolario Italiano Sardo T. II. Cagliari 1852.

- Vincenzo Dorsa, La tradizione greco-latina negli usi e nelle credenze popolari della Calabria Citeriore. Cosenza 1879 p. 8.

- Marcialis, 1. c. s. v. Derselbe führt auch einen fernern sard. Namen der Fledermaus an: pilloni annappau, das wohl soviel als "blinder Vogel" bedentet, und darum den oben besprochenen albanesischen, spanischen, bre- 
Auch für giftig wird die Fledermaius gehalten, worauf sich die Bezeichnung "Scorpion" bezieht, die ihr an einigen Orten beigelegt wird:

Umgegend von Pompei, scorpiun; vielleicht auch hierher zu ziehen: Assergi (Aquila), scurpicciern; Gessopalena (Chieti), scurpenge.'

In Beziehung mit abergläubischen Vorstellungen stehen vielleicht auch das teram. mastripengi, und neapol. cavalocchi; ${ }^{2}$ teram., cavarucchie. ${ }^{3}$

Für die ohne Zweifel bedeutsamen tarent., turtuaja, ${ }^{4}$ turtuvagghia, turtivagghia; 5 lecces. tuagghiola ${ }^{6}$ weiss ich keine Erklärung, so wenig als für die sard. pisgineddu (Lanusei) ${ }^{\top}$ und cisgineddu (Gairo). ${ }^{3}$

tonischen Bezeichnungen anzureihen ist [Vergl. Aneau bei Rolland (1. c. p. 4): „elle (i. e. la chauve-souris) est aveugle comme la taupe ..."]. Annappau ist offenbar part. pass. von annappdre, appannare, offuscare (vgl. Spano, Voc. sardo-ital. s. v.) und dieses abgeleitet von ndppa, pannume, barbdglio, nàppa de sos ojos, cateratta (id. ib.). - Vielleicht ist auf gleiche Weise der erste Teil des gael. ialtag, dialtag zu deuten; Alston (The Fauna of Scotland. Mammalia. Glasgow 1880 p. 9) gibt auch als gael. Bezeichnung einer Spitzmaus, des "Sorex tetragonurus Herm." "daltag, daltagfheior (from Gael., dall, blind, and fheoir, grass"). Vergl. einen der breton. Namen der Fledermaus.

$1 G$. Finamore, l. c.

2 O. G. Costa, Fauna del Regno di Napoli.

3 Gius. Savini, Grammatica e Lessico del Dialetto Teramano. s. v.

1 id. $i b$. - id. Vocabolario zoologico s. v.

- De Vincentiis, Vocabolario del Dialetto Tarantino.

- Gius Costa, Fauna Salentina.

- Efisio Marcialis, 1. c. s. v.

- Briefliche Mitteilung von Dr. Marcialis.

C. J. Forsyth Major. 


\section{Oeber Dialektgrenzen im Romanisohen.}

Die Frage, ob und in welchem Sinne es Sprachgrenzen und Dialekte gibt, ist in den beiden letzten Decennien von hervorragenden Romanisten wiederholt zum Gegenstande eingehender Erörterungen gemacht worden. Da dieselbe nicht nur für die romanische Sprachforschung, sondern für die Sprachwissenschaft überhaupt grofses Interesse bietet, so soll in dieser Zeitschrif über den jetzigen Stand der Frage berichtet werden: es sollen nicht nur die einander entgegen . stehenden Ansichten getreu wiedergegeben, sondern es soll auch ein Urteil über den wissenschaftlichen Wert derselben gewonnen werden.

Der Ausgangspunkt des Streites ist die im Anfange des Jahres I 875 im Gebiete der romanischenSprachen von Ascoli in den Schizzi francoprovenzali1 vorgenommene Ausscheidung und Abgrenzung der sogenannten Franko-provençalischen Gruppe. Ascolis Aufstellungen fanden Paul Meyers Beifall nicht, der Romania 4, 294 ffg. dagegen geltend machte, dafs jeder Versuch einer Einteilung der romanischen Volkssprachen oder besser Volkssprache von vornherein aussichtslos sei: die einzelnen romanischen Sprachen und Dialekte besitzen keine Existenz in der Wirklichkeit, sondern seien ein bloses Gedankending. Die besonderen sprachlichen Merkmale, die man für einen bestimmten Dialekt als charakteristisch hinstelle, erstrecken sich nicht über denselben Raum. Die Ausbreitungsfäche von $a$ decke sich z. B. weder mit der von $b$ noch mit der von $c$ : setze man da eine Dialektgrenze an, wo $a$ aufhört, so sehe man in willkürlicher Weise von der Ausbreitung von $b$ ab; mache man dagegen den Endpunkt von $b$ zum Grenzpunkt, so bleiben $a$ und $c$ unberücksichtigt. Das Zusammenfallen aber von auch nur zwei Ausbreitungsflächen sei ein Fall, der in der Wirklichkeit so gut wie nicht vorkomme. Folglich sei alle auf eine Einteilung in Dialekte verwandte Mühe fruchtlos: aucun groupe de dialectes, de quelque façon qu'il soit formé, ne saurait constituer une famille naturelle.. le dialecte n'est lui - même qu'une conception assez arbitraire de notre esprit.. les caractères, on les choisira arbitrairement selon l'endroit où,

1 Gedruckt im 3. Bande des Archiv. glott. $1878 \mathrm{~S}$. 61 ffg. (s. die Besprechung in der Romania 1875,4 . Band S. 293). 
d'après une idée préconçue, on voudra fixer la limite. Der Dialektologe müsse sich damit begnügen, die Ausbreitung der einzelnen sprachlichen Merkmale festzustellen (faire la géographie des traits linguistiques isolés).

Ascoli antwortete Archiv. glottol. ital. Il 385 in einem Artikel P. Meyer e il franco-provenzale, in dem sich Gedanken finden, die sich unserer Beachtung ebenso empfehlen wie die Schlüsse P. Meyers. Dem Frankoprovençalischen wird S. 6I der Schizzi eine indipendenza istorica gegenüber anderen romanischen Sprachgruppen vindicirt. Es wird Archiv. II 387 betont, dafs die Selbständigkeit einer Mundart nicht dadurch bedingt sei, dafs der betreffende sprachliche Typus eine Reihe von Merkmalen besitze, die anderswo nicht vorkommen: ,i singolari caratteri di un dato tipo si ritrovano naturalmente ripartiti in varia misura fra $i$ tipi congeneri; ma il distintivo necessario dal determinato tipo sta appunto nella simultanea presenza o nella particolar combinazione di quei caratteri“. Es liegen hierin gleichsam Keime, und zwar entwicklungsfähige Keime richtiger Ansichten. Diese Ansichten treten indessen in ihrer Bedeutung nicht recht hervor, weil Ascoli auf die grundlegende Frage der Sprachgrenze nicht näher eingeht (es erscheint dies weniger auffällig, wenn man beachtet, dals der Bericht über die erste auf empirischem Wege untersuchte und festgestellte Sprachgrenze, Tourtoulons und Bringuier's Etude sur la limite géographique de la langue d'oc et de la langue d'oïl, erst im Jahre 1876 erschien). Anderseits scheint Ascoli anzunehmen, dafs es für die Sprachen wie für die naturwissenschaftlichen Disciplinen eine Einteilung in natürliche Gattungen und Arten gebe, und sich damit $\mathrm{zu}$ einer Lehre $\mathrm{zu}$ bekennen, die zu ganz anderen Consequenzen führt, als die zuerst aufgestellte Lehre von der historischen Selbständigkeit der Mundarten (da/s diese Selbständigkeit nur eine relative sein kann, braucht nicht erst gesagt zu werden). In seiner Replik Roman. 5, 504/5 betont P. Meyer noch einmal, dafs der Versuch Ascolis, eine neue Sprachgruppe aufzustellen „ne peut aboutir à la découverte d'une espèce nouvelle duement caractérisée, parceque de telles espèces n'existent pas dans le parler roman . une division suppose des limites, et le parler roman n'offre que des limites extérieures, là où il confine à la mer ou à des idiomes non latins. De limites intérieures, il n'en a pas".

Die von P. Meyer aufgestellten Sätze wurden von G. Paris in einem im Jahre 1888 gehaltenen Vortrage Les Parlers de France (s. Revue des Patois Gallo-Romans II $161-175$ ) in systematische Verbindung gebracht und mit grofser Schärfe verteidigt: besonders wird die ,fusion insensible des parlers betont: die Sprache eines bestimmten Ortes weiche nur sehr wenig von der des räumlich zunächst gelegenen ab. Mit der Entfernung nehmen allmählich die gemeinsamen Züge $a b$, und ebenso unmerklich stellen sich neue ein. In dieser ,masse flottante' Grenzen zu ziehen, Einteilungen vorzunehmen, sei ein Ding der Unmöglichkeit. - Der 
Ansicht P. Meyers und Paris' traten zahlreiche Romanisten bei: A. Darmsteter Revue Critique 1881 II 325 (les dialectes sont des espèces créées par notre esprit et délimitées arbitrairement); Gilliéron Romania I 2, 393 und 1 3, I21; A. Thomas Rom. 8, 469 und II, 45I; Meyer-Lülke Romanische Grammatik I S. 9/10; Gauchat Ztschrift 14, 398; Doutrepont und Haust Mélanges Wallons S. 12; Schuchardt Literaturblatt 13, 304. Ablehnend verhielten sich: Castets Revue des Langues Romanes (Abgekürzt: RdLR) 32, 303; Durand (de Gros) ib. 32, 48; Tourtoulon ib. 34, 130 und im Ganzen auch Joret Roman. 13, 114 ffg., dessen Haltung von Schwankungen nicht frei ist.

Mit neuen Gesichtspunkten trat Gröber Grundrils I $416 \mathrm{ffg}$. an die Frage heran: Von Latium, der Urheimat romanischer Rede, habe die niedere Römersprache keineswegs schrittweise in immer ferneren Orten um sich gegriffen. Die Latinisirung einer römischen Provinz erfolgte vielmehr notgedrungen von auseinanderliegenden Orten aus. Die Voraussetzung der Meyer-Paris'schen Theorie, eine gewisse Dichtigkeit der Bevölkerung und gleichmälsige Verteilung der Einwohner über das Land zu der Zeit, wo die Dialekte sich gebildet haben, sei unerwiesen. Ausgedehnte Strecken waren in Frankreich Jahrhunderte nach der Völkerwanderung Einöden, mit Wäldern und Sümpfen bedeckt. Die Sprache habe sich von gewissen Centren aus über die Umgegend verbreitet, so begreife man die Entstehung historisch bedingter Sprachtypen. Jene Mittelpunkte aufzusuchen sei der eigentliche Sinn der Frage der Sprachgliederung. Die Sprachgliederung sei demnach eine Aufgabe der Sprachgeschichte; die Frage nach der Gliederung der romanischen Mundarten sei auch die Frage nach den Ausbreitungscentren romanischer Sprachen. Die Untersuchung sei schwierig und habe kaum begonnen, die Lösung der Aufgabe gehöre der Zunkunft an. ${ }^{1}$

Unsere nächste Aufgabe ist festzustellen, ob es gelungen ist, auf empirischem Wege durch Beobachtung Sprachgrenzen und Dialekte nachzuweisen und wie sich die Ergebnisse dieser Forschungen zu den theoretischen Ansichten der genannten Gelehrten verhalten. Hören wir G. Paris, so ist die Sache längst entschieden. In seiner Recension des Buches von Adam, Les patois Lorrains, sagt er Roman. 10, 606: M. Adam s'est efforcé de distribuer les patois lorrains en dialectes et sous-dialectes: tentative stérile et dont l'échec montre une fois de plus que toutes ces divisions sont vaines et qu'il faut faire la géographie non des dialectes, mais des traits linguistiques. Der Versuch Adams (dessen Buch übrigens auch schätzbare Eigenschaften besitzt), das Lothringische in Mundarten einzuteilen, beweist indessen nichts weder für noch gegen die Existenz von Dialekten. Derselbe erfüllt keine der Anforderungen, die an eine derartige dialektologische Arbeit gestellt werden müssen: er kommt

1 Wir werden in diesem Artikel noch öfters Veranlassung haben, auf die hier blos skizzirten Ansichten der oben genannten Gelehrten zurückzukommen.

Zoitschr. f. rom. Phil. XVIL. 
wissenschaftlich nicht in Betracht. Dasselbe gilt von der Mehrzahl derjenigen Untersuchungen, von denen Paris Parlers S. 163 sagt: "le travail qu'on a dépensé à constituer, dans l'ensemble des parlers de la France, des dialectes et ce qu'on a appelé des sous-dialectes, est un travail à peu près complètement perdu". Verloren ist die Arbeit, weil sie in der Regel von Dilettanten geleistet wurde, welche ohne die nötige Vorbereitung an eine der schwierigsten Aufgaben linguistischer Forschung herantraten. Selbst die Untersuchung Jorets über die Sprache der Normandie hat die Sache nicht erheblich gefordert, da Joret ein allzu ausgedehntes Gebiet umspannte und sich vielfach auf Angaben aus zweiter Hand angewiesen sah.

Wir unterwerfen zunächst diejenigen Arbeiten einer Prüfung, die zu dem Ergebnis kommen, dafs es Dialektgrenzen gibt. Mit dieser Frage muls nämlich u. E. die methodische Forschung beginnen. Erst wenn dieselbe gelöst ist, kann an die Lösung der Frage nach der Existenz der Dialekte gedacht werden.

II.

In den Mélanges Walllons (Lüttich 1892) hat J. Simon ${ }^{1}$ einen Teil der wallonisch-pikardischen Grenze untersucht und graphisch dargestellt: er hat für fünf Merkmale (die Vertreter von I. ca, ga 2. ce, ty nach Kons. 3. ié 4. $\varepsilon+y$ 5. s vor Konson.) die unter den ältesten und wichtigsten ausgewählt sind, gezeigt, wie die Grenzlinien derselben einander kreuzen, sich einander nähern, dann sich wieder von einander entfernen und sich dabei in einem Raume bewegen, dessen grölste Breite zwischen Binche und Charleroi etwa 15 Kilometer beträgt. Die Untersuchung Simons wird Romania 2 1, 334 einer Kritik unterzogen, die in dem Satze gipfelt, dafs nach der Ansicht Gilliérons der Verfasser „a donné par ses observations et la carte qu'il y a jointe une excellente démonstration de la thèse qu'il voulait combattre". Der Verfasser verzichte selbst darauf, für die Merkmale 3 und 5 eine Grenze zu ziehen „parceque dans la zone frontière ces séries ne sont pas nettement tranchées". Verfasser füge hinzu, dals er dasselbe auch für 2 hätte thun sollen; was 4 betreffe, so sei es auch nicht leicht das Produkt von $\&+y$ $e$ oder $i$ auseinanderzuhalten "dे cause du voisinage de ces deux sons dans l'échelle vocalique". Es bleibe schliefslich I, dessen Grenzen weder mit 2 noch mit 4 zusammenfallen. Diese Kritik scheint nicht ganz unbefangen zu sein. Wenn J. Simon sagt, dafs es z. B. für 3 und 5 nicht möglich sei, eine Grenze zu ziehen, so meint er, dafs an der Sprachgrenze in einer und derselben

1 Les limites du picard et du wallonen Belgique, S. 99-Iro. Simon erzählt, dals er von Hause aus der ťberzeugung war, que toute distinction de dialectes était illusoire, dafs er aber durch die an Ort und Stelle vorgenommene Untersuchung eines besseren belehrt worden sei. 
Ortschaft sich Mischungen finden und die beiden Merkmale neben einander vorkommen, ferner dals bei der Feststellung von 4 der Forscher mit Schwierigkeiten und Unsicherheiten zu kämpfen hat, wie sie demjenigen, der eine lebende Sprache aufzuzeichnen versucht, auf Schritt und Tritt begegnen. Dies ändert aber nichts an der Thatsache, dafs die Grenzlinien aller jener Erscheinungen in die angegebene Zone fallen. In seiner Besprechung derselben Schrift Ztschr. I6, 547 stellt sich P. Marchot zunächst auf den Standpunkt der Romania, geht mit Simon sehr scharf ins Gericht, erklärt in betreff der II von J. Simon aufgestellten Merkmale ,je vais devoir les réduire à bien peu de chose" und reducirt' sie auch glücklich auf zwei oder drei, gibt indessen zuletzt zu, (was für uns die Hauptsache ist), "qu'ils constituent certes une frontière réelle".

Hiermit sind wir an dem entscheidenden Punkte der ganzen Frage angelangt: hier trennen sich die Ansichten in der schärfsten Weise. Die Gegner der Dialekte gehen nämlich von dem Satze aus, dafs eine Sprachgrenze einer mathematischen Linie gleich sein müsse, ${ }^{2}$ welche die in betracht kommenden Merkmale zweier Dialekte in der Weise trennt, dals die Merkmale von A auf der einen, die von B auf der andern Seite liegen. Wird die Linie von dem einen oder dem andern Merkmale überschritten, so ist damit die Grenze aufgehoben. ${ }^{3}$ Der Begriff der limite dialectale wird durch das Zusammenfallen, die coïncidence von mindestens zwei traits linguistiques bestimmt. Ein Dialekt wäre demnach ein

1 Über die Berechtigung dieser Reduction macht der Herausgeber dieser Zeitschrift (s. Ztschrift 16, 549/50) wohlbegründete Vorbehalte. Um jedoch die Erörterung nicht ungebührlich in die Länge zu ziehen, wollen wir mit unsern Gegnern darüber nicht rechten. Marchot gelangt deshalb zu jener Vereinfachung, weil er alle diejenigen Merkmale zurückweist, die er nicht zugleich als spezifische Merkmale (siehe hierüber weiter unten) des Wallonischen und Pikardischen überhaupt betrachten kann. Mit Unrecht. Bei dem jetzigen Stande der Wissenschaft mufs die Untersuchung über die Sprachgrenzen von der Frage, ob und in welchem Sinne es Dialekte gibt, sorgfältig getrennt werden. - Die Merkmale 8- I i bei Simon werden in der Romania überhaupt nicht erwähnt. - Es fragt sich endlich, ob Simon nicht wichtige Merkmale unbeachtet liefs, so freies $e$ und $q$ und sc vor $o, u$.

\& L'objet a rechercher, sagt P. Meyer Romania 8, 469, n'est pas une ligne où viendraient s'arrêter les caractères principaux à l'aide desquels on a constitué un dialecte, une telle ligne ne se rencontrant dans l'intérieur du domaine roman qu'en des cas exceptionnels; ce qu'il faut chercher, c'est la ligne à laquelle vient s'arrêter chacun des caractères observés. S'il se trouve que cette ligne est la même pour plusieurs caractères, ne fât - ce que pour deux, on pourra avec quelque raison fixer une limite dialectale à la ligne où ces caractêres seront venus s'arrêter, mais c'est là une chance à laquelle il ne faut pas s'attendre. - G. Paris bezeichnet die angebliche französich - provençalische Sprachgrenze als eine barrière, eine muraille. - Vgl. noch Gilliéron Romania 12, 395.

3 Paris sagt Parlers S. 164: Tourtoulon et Bringuier ont beau restreindre à un minimum les caractères critiques qu'ils assignent à chacune des deux langues, ils n'ont pu empécher que tantôt l'un, tantôt l'autre des traits soidisant provençaux ne sautât par-dessus la barrière qu'ils élevaient et réciproquement. Cette muraille imaginaire, la science la renverse. 
Complex sprachlicher Erscheinungen, welcher nach allen Seiten durch mindestens zwei zusammenfallende Sprachcharaktere abgegrenzt wäre. $\mathrm{Da}$ aber ein solches Zusammenfallen so gut wie nie vorkomme, 1 so ist die Existenz der Sprachgrenzen und der Dialekte in Abrede zu stellen. Insbesondere ist dies auch der Fall für die pikardisch - wallonische Grenze, für die Simon eine zone intermédiaire annimmt. Der Begriff der Sprachzone involvirt indessen die Verneinung, die Auf hebung der Sprachgrenze. Soweit die Gegner.

Wir bemerken, dafs wir es zunächst mit einer Definition zu thun haben: Wer es von vornherein als Axiom hinstellt, dafs Sprachgrenze und mathematische Scheidelinie identische Begriffe sind, mit dem ist über die Sache nicht weiter zu streiten. Man kann nur verlangen, dafs derselbe, um Mifsverständnissen und zeitraubenden Erörterungen vorzubeugen, die Ausdrücke, deren er sich bedient, genau definirt, dals deutlich gesagt werde: „Für mich gibt es keine Sprachgrenze, da für mich Sprachgrenze soviel ist als mathematische Linie", u. s. w.

Und nun eine zweite Bemerkung: die Verfechter der Existenz von Sprachgrenzen und Dialekten haben jene Definition nicht aufgestellt und ihre Richtigkeit nie anerkannt. Tourtoulon, ${ }^{2}$ der als der hervorragendste unter den Gelehrten bezeichnet werden darf, die für die Existenz der Sprachgrenzen eintreten und sich auch gleichzeitig um die thatsächliche Erforschung derselben grofse Verdienste erworben haben, - 'sagt (Etude sur la limite géographique de la langue d'oc et de la langue d'oil, 1876 , S. 16. A. 2): La langue d'oc et la langue d'oil s'altèrent en se rapprochant. Représentons par $a, b, c, d$ quatre villages situés sur une ligne perpendiculaire à notre limité, laquelle passerait entre $b$ et $c$; l'idiome de $a$ offre tous les caractères de la langue d'oc; $b$ a perdu un ou deux de ces caractères; $c$ présente au contraire tous les caractères d'oïl moins un ou deux; et $d$ est de la langue d'oïl pure; und S. 87 A. 3. nous ne croyons pas avoir besoin de dire que la limite de deux langues ne peut pas être une ligne dans le sens géométrique du mot, comme l'est une limite politique ou administrative.

1 Nach P. Meyer können natürliche Grenzen wie Meere, Flüsse, Gebirge auch sprachlich trennend wirken.

2 Schuchardt spricht Literaturbl. 1 3, 304 von den Leuten die das, was nur Hülfsconstructionen sind, um die Fülle der Erscheinungen zur Erkenntnis zu bringen, als Grenzlinien in die Erscheinung selbst hinein projiciren, von den bureaucratisch - pedantischen Geistern, die für alles das Schlagwort Ordnung bereit halten und die Nüancen verschmähen. In diesem Zusammenhange wird Tourtoulons Name genannt. Tourtoulon mag nun allerdings von irrigen Ansichten über die Klassifizirung der Sprachen im allgemeinen nicht frei sein. Prüf man jedoch seine dialectologischen Arbeiten (und dies allein ist das Entscheidende), so trifft ihn jenes absprechende Urteil nicht. T. zieht nicht feste Trennungslinien, sondern weist historische Sprachgrenzen nach, was etwas grundverschiedenes ist. $\mathrm{Ob}$ nicht vielmehr denjenigen Gelehrten der Sinn für die Nüance fehlt, die sich eine Sprachgrenze nicht anders denn als einen "festen Strich" zu denken vermögen? 
La première flotte forcément, sur presque tous les points de son parcours, entre deux centres de population. Auch in diesem Sinne lälst sich nach Tourtoulon nicht immer eine Grenze angeben. Daher kommen zones intermédiaires und idiomes mixtes vor: ${ }^{1}$ nous avons indiqué d'un côté la ligne précise où la langue d'oc présente un ensemble de caractères qui ne permettent pas de la méconnaître; de l'autre, la ligne correspondante pour la langue d'oïl, laissant entre les deux le domaine de l'idiome mixte livré à la discussion des philologues (S. 17).

Wenn auch der Fall nicht ausgeschlossen ist, dafs sich eine Sprachgrenze als eine Linie darstellen kann, die einer mathematischen mehr oder weniger gleichkommt, so ist es doch von vornherein wahrscheinlich, dafs dieselbe in der Regel eine Zone sein wird. Die Frage ist für uns die, in welchem Sinne und mit welchem Rechte man von einer Zone als von einer Sprachgrenze reden darf.

Betrachten wir die Thatsachen rein äufserlich, so wie sie gleichsam sinnlich wahrnehmbar sind, so werden wir sagen, dafs jene Zone ein verhältnifsmälsig kleiner Raum ist, in dem sprachliche Merkmale Veränderungen erleiden, die an Zahl und Bedeutung diejenigen weit übertreffen, die in den übrigen Teilen des betreffenden Sprachgebietes vorkommen. Wir betonen, dafs es nicht blofs auf die Zahl, sondern auf die Bedeutung, den Wert der Merkmale ankommt. Der Einwand, da/s diese Wertschätzung subjektiv sei, dafs aufserhalb jener Zone zahlreiche lautliche Veränderungen sich oft von Dorf zu Dorf zeigen, dafs demnach die Grenze willkürlich angesetzt sei und ebenso gut an eine andere Stelle verlegt werden könne, - ist unberechtigt. $\mathrm{Er}$ wird noch weiter unten in einem andern Zusammenhange erwogen werden. Es soll hier nur darauf hingewiesen werden, dals die zahllosen Lautnüancen, die sich von Ort zu Ort finden und deren Entstehung oft in die jüngste Zeit tällt, den individuellen Lautunterschieden ähnlich sind, die oft innerhalb der engsten Sprachgemeinschaft zwischen einem Individuum und dem andern wahrnehmbar sind. Es ist ein abstract-logischer, aber unhistorischer und daher unrichtiger Standpunkt, alle Lautunterschiede eines Dialektes als gleichwertig zu betrachten.

Unsere Gegner nehmen an, dafs jene traits linguistiques sich unabhängig von einander entwickelt haben. Wenn die Endpunkte ihres Ausbreitungsgebietes in jene Gegend zwischen Binche und Charleroi fallen, so sei dies ein Zufall.2 Für sie „il n'y a que la topographie des faits linguistiques pris isolément qui possède une réalité" (s. Gauchat, Ztschrift 14, 398). Wir dagegen schliefsen

I Häufig ist nach T.S. 8 l'existence simultanée, remontant à un temps immémorial, d'un dialecte d'oil et d'un dialecte d'oc dans un même village. In diesem Falle ist also die denkbar schärfste Grenze vorhanden.

2 Paris spricht Parlers S. 164 von der von Tourtoulon erforschten französisch-provençalischen Sprachgrenze als passant par des points absolument fortuits, 
aus der Thatsache, dafs jene Endpunkte oder Linien räumlich nahe bei einander liegen, und aus der andern, dafs dieselben lauthistorisch bedeutsame Unterschiede zweier ausgedehnter Sprachcomplexe zum Ausdruck bringen, dafs jene Lautgrenze kein $\mathrm{Zu}$ sammentreffen von points fortuits, sondern in ihrer Gesamtheit historisch bedingt ist. Das Entscheidende ist, ob die Berechtigung zu diesem Schlusse anerkannt wird oder nicht. Es handelt sich in letzter Instanz um die Anwendung der Kategorie der Kausalität ${ }^{1}$ auf eine Reihe historischer Thatsachen. Etwas unmittelbar gegebenes ist die Sprachgrenze nicht, so wenig ein zwischen historischen Thatsachen angenommener Causalnexus, so wenig ein Lautgesetz etwas unmittelbar gegebenes ist. Und doch besitzt ein Lautgesetz Realität, ist nichts durch Menschenwitz ersonnenes, kein Produkt willkürlicher Voraussetzungen. Desgleichen ist eine Sprachgrenze kein blofses Gedankenprodukt, keine willkürliche in die Wirklichkeit hineingetragene Combination. Sprachgrenzen sind zu einer gegebenen Zeit die Punkte oder Linien, wo sich zwei relativ selbständige Sprachcomplexe berühren, sei es dafs jene Linien sich schneiden, zusammenfallen oder neben einander herlaufen. Sie sind in ihrer Gesamterscheinung Produkte zusammenwirkender Faktoren. Es besteht demnach für uns zwischen dem, was für andere nur faits linguistiques isolés sind, ein geistiges Band, ein historischer Causalnexus. Zur Feststellung jener Grenzen ist die rein historische Methode anzuwenden, und die Gewilsheit, mit der eine solche Sprachgrenze festgestellt werden kann, entspricht dem Malse von Gewirsheit, welches den Ergebnissen der Geschichtswissenschaft überhaupt zukommt. Demnach ist das mathematische Zusammenfallen der Merkmale an und für sich nicht das Entscheidende, ja es könnte ein solches Zusammenfallen ein Werk des Zufalls und folglich für die Erkenntnis des Gewordenen belanglos sein.

Was hier von der pikardisch-wallonischen Sprachgrenze gesagt wird, gilt natürlich im Allgemeinen von jeder andern, und dem Nachweise, dafs unserer Auffassung der pikardisch - wallonischen Grenze ein Irrthum oder eine Täuschung zu Grunde liegt, müIste, um die Frage principiell zu entscheiden, sich der Nachweis anschliefsen, dals unsere Beurteilung der Dialektgrenzen, die im Folgenden noch erwähnt werden sollen, ebenfalls unbegründet ist.

1 Nach Gilliéron Romania 12, 395 ist der Schlufs auf eine gemeinsame Ursache 2 weier traits linguistiques nur zulässig, wenn beide zusammenfallen. Es wird nicht gesagt, wie der Fall zu beurteilen ist, wenn eine grölsere Anzahl wichtiger Merkmale im Raume nahe bei einander liegen. Der cas de coïncidence wird dann S. 396 als etwas zufälliges (fortuit) hingestellt. Endlich wird constatirt, dafs le cas de coïncidence des frontières de deux faits phonétiques häufiger sei que ne le ferait supposer son caractère de fortuité. Diese Erscheinung wird daraus erklärt, dals die betreffenden patois nicht in ihrem état normal de développement et d'indépendance sind (s. weiter unten), dafs jene coïncidence eine Folge der Beeinflussung durch andere Mundarten ist. 
Die Art und Weise wie wir uns die Entstehung jener Grenze denken, lärst sich mit wenigen Worten angeben. Wir nehmen mit Gröber an, dafs von zwei auseinander liegenden Centren, einem pikardischen und einem wallonischen aus, zwei verschiedene Sprachtypen (ihre historische Stellung ist mafsgebend) sich nach allen Seiten hin ausgebreitet haben. Die Berührungspunkte, resp. Linien beider sind eben die pikardisch-wallonische Sprachgrenze. In welcher Weise die Berührung sich vollzieht, durch Linien, die zusammenfallen oder sich schneiden oder neben einander herlaufen, ist von unserm Standpunkte vollständig gleichgültig. Das Wesentliche ist, dafs an den betreffenden Punkten zwei von verschiedenen Centren ausgehende Sprachkreise sich begegnen. Den Nachweis, von welchen Centren die Bewegung ausging, sind wir freilich noch nicht im stande zu führen.

Es ergibt sich aus dem, was über den Ursprung dieser pikardisch - wallonischen Sprachgrenze gesagt wurde, dafs dieselbe viele Jahrhunderte alt sein kann und höchst wahrscheinlich alt ist. Sie ist zeitlich bedingt. Es ist mithin kein Grund abzusehen, weshalb eine derartige Grenze im Laufe der Zeit nicht Veränderungen unterworfen sein sollte: es wohnen ja an der Grenze Leute, die einerseits pikardisch, anderseits wallonisch reden, so dafs mit der Zeit Mischungen unvermeidlich waren. Will man ein richtiges Bild von der geschichtlichen Entwicklung der Grenze gewinnen, so wird man sie so reconstruiren müssen, wie sie in der Zeit ihrer Entstehung beschaffen war. Es sind zu diesem Zwecke geschichtliche Untersuchungen unerläfslich. Es ist ein verkehrtes Verfahren, auf Grund der heutigen sprachlichen Beschaffenheit einer Mundart ohne weiteres die Frage nach der Existenz oder Nichtexistenz eines Dialektes oder einer Sprachgrenze beantworten zu wollen. Die Notwendigkeit einer derartigen historischen Voruntersuchung wird in unserem Falle auch von der Romania zugestanden, die ihre Kritik der Arbeit Simons mit den Worten schliefst: Que serait-ce si nous connaissions les influences historiques qui ont agi sur le développement des parlers locaux, les conditions de leur rencontre et de leur expansion? Diesen Worten scheint die Voraussetzung zu Grunde zu liegen, es werde eine „enquête historique“ zu dem Ergebnis führen, dafs in der Vergangenheit noch weit weniger als in der Gegenwart von einer Sprachgrenze die Rede sein könne, während wir nicht einsehen, warum die Untersuchung nicht zu dem entgegengesetzten Ergebnis führen sollte. Gerade darin dafs heute, Jahrhinderte nachdem pikardische und wallonische Redeweise mit einander in Berührung gekommen sind, die Berührungspunkte und Linien so scharfe Spuren hinterlassen haben, sehen wir einen Beweis für die Richtigkeit unserer Auffassung.

Nach P. Marchot Revue de Philologie Française 5, 222 gibt es auch eine wallonisch-lothringische Sprachgrenze: le Lorrain, appelé en Belgique gaume, cesse d'être compréhensible pour un Wallon. Il englobe en Belgique à peu près l'arrondissement de 
Virton avec Virton, Etalle et Florenville comme centres principaux. Bouillon d̀ l'est et Neufchâteau au nord sont essentiellement wallons. Witry est point frontière du domaine wallon par rapport au lorrain. Anlier, à deux lieues au sud, appartient déjà à ce dialecte. Il ne sera pas sans intérêt de mentionner que les habitants de cette frontière linguistique se rendent compte qu'il y a là un assez brusque changement de dialecte: $j$ 'ai du reste personnellement constaté le fait à Anlier, Habay la Neuve et Habay la Vieille, oì je ne comprenais plus le patois courant. In seinem 1892 erschienenen Buche, Phonologie détaillée d'un patois wallon (Paris, Bouillon), bemerkt M. in demselben Sinne S. 88 , dafs la frontière du dialecte lorrain n'est qu'd sept ou huit lieues de St. Hubert, au sud de Neufchâteau. ${ }^{1}$

In einer im Jahre 1887 im 5. Bande der Französischen Studien erschienenen Arbeit über die Ostfranzösischen Grenzdialekte zwischen Metz und Belfort habe ich gezeigt, dafs die an der deutschen Sprachgrenze gelegenen Mundarten sich in der Richtung von Norden nach Süden in der ungezwungensten Weise in sieben Gruppen gliedern, die sich von einander durch mehrere sprachliche Merkmale abheben. An einem Punkte (auf der Grenze der Gruppen $B$ und C) habe ich von einem Dorfe (Moussey) bis zum nächsten 4 Kilometer entfernten (Réchicourt) das plötzliche Auftreten von fünf neuen Merkmalen constatirt, die darauf in dem gesamten Gebiete von $\mathrm{C}$ constant blieben. In andern Gruppen wurde an den Berührungspunkten ein Schwanken festgestellt, das sich hier, wo die Sprachgruppen selbst eine verhältnifsmälsig geringe Ausdehnung besitzen, auf wenige Kilometer beschränkt. So wurde z. B. ein für $\mathrm{C}$ aufgestellter lautlicher Zug auch in zwei Ortschaften von $D$ nachgewiesen. Die Sprachgrenzen wurden nur an wenigen Punkten, nicht in ihrer ganzen Ausdehnung festgestellt (wer das Mühsame einer solchen Arbeit aus eigener Erfahrung kennt, der wird es entschuldigen, dafs nicht mehr geleistet wurde). Im Osten ist das Gebiet durch die deutsche Sprachgrenze abgeschlossen, im Westen sind die Sprachverhältnisse nicht untersucht worden. In der Anzeige dieser Schrift sagt G. Paris Romania 16, 609: sur les divisions qu'il établit, l'auteur fait lui -même quelques réserves que nous serions disposé a accentuer, mais elles lui ont rendu son travail plus facile et permettront aussi de l'utiliser plus commodément. Meine Vorbehalte beziehen sich auf meine ganze Auffassung der Dialektfrage, besonders darauf, dafs für mich eine Dialektgrenze nicht notwendig eine Linie ist. Wenn aber Paris andeutet,

1 Bei der Aufnahme dieser Sprachgrenze wird besonders auf folgende Punkte zu achten sein: enk; sc vor $o, u$; freies $\phi$ und $\delta$; gedecktes $\ell$ und $Q$ vor $r$ und $s$; die Vertreter von $u n$ in absoluter Stellung, von ongle, mieux und von den Wörtern, in denen im Wallonischen intervokalisches $l \mathrm{zu}^{y}$ wird, wie aile, toile, mâle. Dabei wird P. Marchots Arbeit über die Patois du Luxembourg Central (Revue des Pat. gallo-rom. 4, 17-32) von Nutzen sein. Einige der dort erwähnten Ortschaften, wie z. B. Recogne, befinden sich schon in dem Bereiche der wallonisch-lothringischen Sprachgrenze. 
dafs jene Einteilung im Wesentlichen nur dem Zwecke diene, die Darstellung zu erleichtern, so muls ich mich gegen diese Auffassung verwahren. Der Unterschied zwischen dem Standpunkte Paris' und dem meinigen läfst sich dahin zusammenfassen, dafs für Paris jene Einteilung in Gruppen wissenschaftlich bedeutungslos ist und höchstens den Wert eines Rahmens hat, der die sprachlichen Einzelheiten in bequemer Weise zusammenhält, während für mich jene Gruppen selbst die wichtigste sprachliche Erscheinung des ganzen Gebietes sind, hinter welche alle Einzelerscheinungen all Wert und Bedeutung weit zurücktreten.1

Die Grenze zwischen der sechsten und der siebenten jener Gruppen kann mit Fug und Recht zugleich als die Grenze zwischen dem Lothringischen und dem Burgundischen betrachtet werden. Da der Welsche Belchen als gewaltiger Markstein zwischen beiden Gebieten liegt, könnte man einwenden, dals die Sprachgrenze durch dieses natürliche, den Verkehr hemmende Hindernis bedingt sei, wie ja auch P. Meyer zugibt, dals natürliche Grenzen auch sprachlich trennend wirken können. Paul Passy hat nun neuerdings in der Revue de Philologie française et provençale 6,148 ffg. die Existenz der lothringisch-burgundischen Sprachgrenze an einem anderen Punkte nachgewiesen, zwischen dem Val d'Ajol und Plombières. Passy führt aus: Si on monte du Val d'Ajol aux premières maisons de la Montagne, à un quart d'heure de marche, on trouve chez ces gens qui vont à l'école, au marché à Plombières et vivent en rapports constants avec les gens de Granges et de Plombières un patois absolument différent. Puis lorsqu'on parcourt ce vaste territoire du Val d'Ajol, on est tout aussi étonné de ne pas y trouver de variations dialectales marquées. Et si on passe du Val d'Ajol à Fougerolles ou à Saint - Bresson, on trouve une différence normale, bien moins profonde que celle entre Plombieres et le Val d'Ajol (mit andern Worten Fougerolles und Saint-Bresson liegen wie das Val d'Ajol im Gebiete der Franche-Comté, Plombières im Lothringischen Sprachgebiete). Die wichtigsten unterscheidenden

1 C. This Die Deutsch-Französische Sprachgrenze im Elsals (Strafsburg 1888) bemerkt $S .47$, dafs seine nachträglichen Forschungen $2 u$ gleichen Ergebnissen geführt haben. In der Deutschen Litteraturzeitung 1888, S. 1220 weist er darauf hin, dafs das Bewufstsein jener Sprachgrenzen im Volke lebendig sei. Die Bewohner von Baronville (Grenzortschaft der Gruppe A gegen $\mathbf{B}$ hin) wissen sehr gut, dafs in Konthil (Grenzortschaft von Gruppe B) ein anderes Patois als das ihrige gesprochen wird, und umgekehrt, während z. B. der Bewohner von Baronville seine Mundart für identisch hält mit der der westlich und nordwestlich gelegenen Ortschaften und der Bewohner von Konthil die seinige von der der südlich gelegenen Ortschaften nicht unterscheidet. Ebenso verhält es sich auch mit Schirmeck (Gruppe C) und Rothau (Gruppe D) und mit allen übrigen Grenzortschaften. Wenn die Bewohner solcher Ortschaften sich auch gegenseitig mehr oder weniger leicht verstehen, so beruht dies lediglich auf der durch den Verkehr erworbenen Kenntnis der nachbarlichen Sprachverschiedenheiten, aber nicht auf Sprach. mischung. Im Volksmunde führen diese Mundartgruppen besondere Namen: so heifst die Gruppe A „le Messin“, B „le Sano“ (le Saulnois), C „le Vosgien“. 
Merkmale sind: burg: $t s, t z$ (aus $r t, r d$ ); betontes $a$ in 1 . sing. Praes. Indicat.; betontes $a$ im Infinit. der Verba auf -are (= lothr. $e)$; das Pronom. der I. sing. und plur. $i$ und no (lothring. sing. und plur. $\left.\check{z}_{f}\right) .1$ Passy fährt fort: Il est évident qu'entre Granges et Plombières d' une part et. le Val d'Ajol de l'autre, il y a une limite dialectale. Ce fait seul est intéressant à constater, car il passe pour peu commun. Mais ce qui le rend plus curieux, c'est que la limite dialectale ne coïncide pas avec des limites politiques anciennes ou modernes.. Le Val d'Ajol faisait partie de l'ancienne Lorraine et se rattache aujourd'hui au département des Vosges, tandisque Fougerolles et Saint-Bresson appartiennent à la FrancheComté.

Über die allgemein bekannte Etude Tourtoulons und Bringuiers über die limite géographique de la langue d'oc et de la langue d'oïl (1876) beschränken wir uns auf folgende Bemerkungen:

a) Paris sagt Parlers S. I64: ils ont eu beau restreindre dे un minimum les caractères critiques qu'ils assignaient à chacune d'elles, ils n'ont pu empêcher que tantôt l'un tantôt l'autre des traits soi-disant provençaux ne sautât par dessus la barrière qu'ils élevaient, et réciproquement. Auf das, was oben über den Begriff der Sprachgrenze gesagt wurde, kommen wir hier nicht zurück. Was die geringe Zahl der Merkmale betrift, so ist zu beachten, dals eine Beschränkung auf ein Minimum deshalb geboten war, weil jene traits für die gesammte langue d'oc im Gegensatz zur gesammten langue d'oïl Gültigkeit haben sollten. Die Frage, ob es in Frankreich zwei verschiedene Sprachen und demnach zwei Sprachgrenzen gibt (wir haben bis jetzt Sprach- und Mundartgrenze als synonyme Ausdrücke gebraucht), lassen wir vorläufig auf sich beruhen. Die Ansicht, die wir hier vertreten, ist die, dafs es Mundartengrenzen gibt, und es ist unzweifelhaft, dals, wenn man die französisch - provençalische Sprachgrenze in ihrer ganzen Länge in Segmente teilt und jeweilig nur das nördlich und südlich von diesem Segment (tracé partiel) gelegene Gebiet einer vergleichenden Betrachtung unterwirft, die Zahl der unterscheidenden Merkmale sich beträchtlich vermehren lälst. Dazu kommt, dals es irrig ist, die Merkmale blos zu zählen, hierauf ist mit Recht von Tourtoulon hingewiesen worden. So z. B. genügt der Paroxytonismus des Provenzalischen im Gegensatze zum Oxytonismus des Französischen an sich schon, um beiden Sprachcomplexen ein verschiedenes Gepräge aufzudrücken.

b) Die Lösung der Frage, ob es eine ,ligne de démarcation tranchée" zwischen den Mundarten von oïl und oc gibt, hängt keineswegs von der Thatsache an sich ab, ob es Mittelglieder (formes transitoires) zwischen beiden gibt, sondern malsgebend ist die Art

1 Auf sprachliche Einzelheiten einzugehen, ist hier nicht der Ort. Wer sich ein selbständiges Urteil über diese Dinge bilden will, wird ohnehin von den hier erwähnten Arbeiten (sie sind nicht zahlreich) in eingehender Weise Kenntnis nehmen müssen. 
und Weise, wie sich diese Mittelglieder gebildet haben. Sind sie, um mit Paris zu reden, produits spontanés der Orte, wo sie auftreten, so mag für die Bezirke, wo solche Mittelglieder vorkommen, die Auffassung richtig sein, dals es keine différence tranchée gibt. Sind dagegen, wie sich dies aus vielen Stellen der Arbeit Tourtoulons ergibt, diese Mittelglieder erst verhältnilsmärsig spät aus dem Zusammenfliefsen von Flementen beider Sprachen gebildet, so können diese spätgeborenen Mischprodukte gegen die ursprüngliche Verschiedenheit beider Sprachen nichts beweisen. ${ }^{1}$

c) P. Meyer gibt Romania 6,632 zu, dafs en certains lieux, notamment dans la Gironde, la limite des deux langues s'établit facilement, sans hésitation. Er meint indessen, dafs diese Grenze sich erst verhältnismäfsig spät infolge der Einwanderung zahlreicher Familien aus dem Norden, insbesondere aus der Saintonge, gebildet habe, so dafs sich jetzt da eine limite assez précise finde, wo man sie früher umsonst gesucht hätte. Aurserdem sei es gewirs, dấs au moyen-âge la langue d'oc s'étendait assez loin au nord de la Gironde et se confondait avec la langue d'oil à peu près entre Barbezieux et la Charente. ${ }^{2}$ In wie fern alle diese Angaben als gesichert betrachtet werden können, bin ich nicht in der Lage zu controliren. $\mathrm{Ob}$ indessen die Entstehung des gesamten Teiles der Grenze, von dem Tourtoulon RdLR 34, I 72 sagt: on ne saurait nier que la démarcation n'en soit nette sur un parcours d'au moins 200 kilomètres in der angegebenen Weise zu erklären sei, möchte ich bezweifeln. Wenn des weiteren Meyer andeutet, dafs überall, wo heute Sprachgrenzen vorhanden sind, dieselben erst in späterer Zeit entstanden sind, so hängt dies mit Ansichten zusammen über l'etat normal der Sprache, le libre développement du latin, l'impossibilité, dans les cas normaux, d'établir des limites dialectales, die wir nicht teilen und auf die wir noch weiter unten zurückkommen werden. Über den von Tourtoulon so genannten dialecte sous-marchois urteilt Meyer: l'existence de cet idiome mixte et sans fixité [bei dem nach Tourtoulon von einer eigentlichen fusion nicht die Rede sein kann] s'explique naturellement par des rapports plus fréquents qu'ailleurs entre deux populations ayant eu antérieurement chacune son dialecte. Je suis convaincu que l'usage d'un tel idiome ne remonte pas à une époque bien ancienne. Hier hätte also früher eine Sprachgrenze bestanden, die erst neuer-

1 Auf die Frage von Paris: Comment expliquer cette étrange frontière qui de l'ouest à l'est couperait la France en deux? hat Tourtoulon richtig geantwortet (Rev. des LR 34, 172): un fait est ou n'est pas; il serait un étrange savant, celui qui éliminerait de la science tout ce qu'il n'explique pas. Darauf gibt er selbst eine sehr wahrscheinliche Erklärung: ne peut-on pas admettre que de larges espaces boisés et inhabités aient longtemps séparé les populations du Nord de celles du Midi, que les parlers des unes et des autres se seraient développés dans des sens différents et que le défrichement ayant rétréci, puis supprimé la zone déserte, les idiomes se soient rencontrés?

2 Es hätte demnach bereits im Mittelalter eine Grenze zwischen dem Französischen und dem Provençalischen gegeben. 
dings durch Sprachmischungen verwischt worden wäre. Hier wäre man demnach berechtigt, das Gegenteil von dem anzunehmen, was P. Meyer für die Sprachgrenze in der Gironde annimmt, d. h. es hätte früher da eine limite assez précise gegeben, wo man heute vergeblich darnach sucht. Aus jener Recension der Romania gewinnen wir den Eindruck, dals P. Meyer die Existenz der französisch-provençalischen Sprachgrenze zugibt, weil er eben angesichts der Ergebnisse der Tourtoulon'schen Forschung nicht umhin kann, dieselbe zuzugeben, dafs er dies aber gleichsam nur widerstrebend mit zahlreichen Einschränkungen und Vorbehalten thut. Für uns ist das Zugeständnis entscheidend, dafs es Stellen gibt, wo die Grenze s'établit nettement, sans hésitation. Ist dies aber der Fall, so ist dies eine aufserordentlich wichtige Thatsache. Der Nachweis dieser Grenze ist dann das Hauptverdienst der Arbeit Tourtoulons, und wir begreifen nicht, wie P. Meyer sagen kann, dafs der Wert jener Forschung in der Bestimmung der Grenzen einer gewissen Anzahl von Merkmalen zu suchen ist, "la constatation des points jusqu'où ces caractères se manifestent. Que l'on affirme ensuite que la ligne qui passe par ces points est la limite ou le lieu de jonction de deux groupes de dialectes, c'est une affaire d'appréciation qui n'a qu'une importance secondaire". Das, was hier als belanglos dem subjektiven Ermessen anheim gegeben wird, ist für uns eben die Hauptsache. Gibt es Sprachgrenzen oder nicht? Wenn ja, so ist die Festsetzung der Sprachgrenze die Hauptsache, wichtiger als die Bestimmung der Ausbreitung der einzelnen traits dialectaux, wenn anders das Allgemeine, Umfassende wichtiger ist als die Einzelerscheinung. ${ }^{l}$

Professor Hunziker hat in den Basler Nachrichten (vgl. dazu Gauchat Litteraturblatt 13, 17) die Ansicht geäufsert, dafs die Mundart des Berner Jura in den wesentlichsten Punkten mit den französischen übereinstimme, während von der Nordgrenze des Kantons Neuenburg und vom St. Immerthal südwärts die ganze übrige Westschweiz zur francoprovençalischen Gruppe gehöre. Hunziker stützt sich dabei auf die Forschungen von J. Zimmerli

1 Nach Suchier Grundrifs I 592 gehört es zum Begriff der Sprachgrenze oder Mundartgrenze, dafs an derselben Linie sich mehrere sprachliche Züge von einander abheben, ein Fall, der auf dem Boden Frankreichs nur ausnahmsweise vorkomme. Mit den letzten Worten griff S. der Forschung vor: nach den neueren Untersuchungen dürfte der Fall durchaus nicht selten sein. Jene Linie falst S. übrigens nicht als tine mathematische, denn S. 597 erkennt er sowohl die französisch-gascognische als auch die französisch-provençalische Grenze als echte Sprachgrenzen an. - L. c. S. 592 bemerkt Suchier: Man kann die Mundarten eines Landes in verschiedener Weise darstellen, je nachdem man Lokalitäten oder sprachliche Züge als Einteilungsprinzip wählt, und betont, dals er dem zweiten Prinzip den Vorzug gebe. Die Darstellung einer Dialektgrenze in unserem Sinne fält indessen unter keinen dieser beiden Gesichtspunkte: es ist eine historische Gesammterscheinung, deren Ausbreitung auf empirischem Wege festgestellt wird. Von einer willkürlichen Wahl von sprachlichen Zügen oder Lokalitäten als Einteilungsprinzip kann dabei keine Rede sein. 

provençalische grenzen. Anderseits darf dieses $a$ auch nicht ohne weiteres als Beweis gegen die von Ascoli versuchte Abgrenzung einer historisch selbständig entwickelten Franco-provençalischen Gruppe ins Feld geführt werden. Denn höchst wahrscheinlich ist jenes in manchen Strichen der Franche-Comté vorkommende $a$ erst in verhältnismäfsig später Zeit aus \& hervorgegangen, ${ }^{1}$ während das franco-provençalische $a$ alt und unabhängig von dem burgundischen entstanden ist. Es liegt hierin ein neuer Beleg für den oben aufgestellten Satz, dafs die Lösung der Frage nach der Existenz oder Nichtexistenz einer Sprachgrenze oder eines Dialektes in vielen Fällen ohne historisch-kritische Untersuchungen nicht möglich ist. ${ }^{2}$

Noch zwei Sprachgrenzen erwähnt Tourtoulon RdLR 34, 147 und 148: Sur les limites de l'ancien Roussillon, entre Leucate et Salces, petites villes qui ne sont séparées que par une distance de 13 Kilomètres, le catalan succède brusquement au languedocien. ${ }^{3}$

Entre le catalan et l'aragonais la transition est aussi brusque qu'entre le languedocien et le catalan. Sur la route de Barcelone à Sarragosse le petit village d'Almacelles marque l'extrême limite du catalan et, après un intervalle à peu près inhabité de 18 Kilom., on rencontre Binefar, premier village aragonais. 4

J. P. Durand (de Gros) gibt RdLR 33, 48 und 72 an, dals eine ligne linguistique das Departement Aveyron in zwei Teile schneide, östlich le parler caussenard (in der Landschaft Causse), westlich le parler ségalin (in der Landschaft Segalar). In der ganzen östlichen Hälfte des Rouergue mit den arrondissements Espalion, Milhau und einem Teile der arrondissements Rodez, Villefranche und Saint-Affrique "le patois est d'une uniformité presque parfaite et marqué par des caractères multiples et très particuliers qui le séparent de la bande rouergate occidentale". Eine nach streng philologischer Methode gemachte Grenzaufnahme gehört auch hier zu den Desiderata der Wissenschaft. Nach Durands

1 Auch Suchier vertritt Grundrifs I 594 diese Ansicht: vielfach hörte ich in der Franche-Comté nicht $a$, sondern $\&$ sprechen, d. h. ein sehr offenes an $f$ anklingendes $a$.

2 Zur Aufstellung von Kriterien, wie die so eben aufgezählten, ist ein genauer Ubberblick über ein weites Gebiet unerlärslich. Es mag also leicht das eine oder das andere jener Merkmale sich bei näherer Prüfung als wertlos erweisen. Der billig urteilende Leser wird indessen aus vereinzelten Versehen, die in diesen Dingen sehr schwer zu vermeiden sind, den Schlurs nicht ziehen dürfen, dals der eingeschlagene Weg überhaupt ein Abweg, die allgemeinen Voraussetzungen, von denen ausgegangen wird, unrichtig, das Ziel selbst unerreichbar sei.

3 Tourtoulon fügt hinzu: Ici deux des principes posés par M. Paris sont nettement contredits par les faits: il n'y a pas de fusion entre les deux idiomes juxtaposés et la limite linguistique coïncide avec la limite politique.

- Tourtoulon bemerkt Etude sur la limite, S. 6. Boucherie habe ihm versichert que sur certains points du département de la Charente, il avait constaté la juxtaposition du limousin et du saintongeois se côtoyant sans se confondre. Auch hier fehlen genaue Angaben. 
Zeugnis ib. S. 77 ist auch nach Norden das Rouergue durch eine scharfe Sprachscheide von der Auvergne getrennt: dès qu'il (der Einwohner der Auvergne) aura franchi les deux lieues de montagne qui séparent le village rouergat de Lacalm du village auvergnat de Chaudesaygues, il ne comprendra rien de ce qu'il entendra. $\mathrm{Da}$ hier Berge die Grenzscheide bilden, so liegt hier einer von den auch von P. Meyer Romania V 505 A. I anerkannten cas peu fréquents vor, où un fait physique établit une limite. Durand gibt im einzelnen die Merkmale an, die die Sprache des Rouergue von der der Auvergne scheiden.

Tourtoulon verdanken wir endlich auch wertvolle Angaben über die italienisch-provençalische Sprachgrenze zwischen Ventimiglia und Nizza. RdLR 34, $156 \mathrm{ffg}$. wird ausgeführt: dès qu'on a franchi les falaises de la pointe de la Murtola (bei Ventimiglia), limite du territoire français, la langue qui s'était peu modifiée depuis Gênes et presque pas depuis Savone change brusquement. Wir begegnen der Mundart von Mentone, welche aus Provençalisch und Französisch gemischt ist. Tourtoulon zählt nicht weniger als zehn Merkmale auf, von denen fünf als besonders wichtig bezeichnet werden, „parcequ'ils frappent à peu près également, dès qu'on a franchi la frontière française. Ces caractères apparaissent brusquement à Garavan, faubourg de Menton situé près de la frontière française actuelle qui fut jadis la frontière du comté de Nice et de la principauté de Monaco". Die fünf Merkmale sind: 1) Ventimiglia wahrt den Wörtern die volle Silbenzahl des Lateinischen (venire, vendere, póvero), Mentone kürzt sie (veni, vende, paure). 2) In Vent. endigen die Wörter vokalisch (gato, dente), in Ment. Konsonantisch (gat, dent). 3. lat. $\bar{u}$ klingt in V. $u$, in M. ü. 4) Die Konjugation ist in Mentone fast ganz provençalisch. 5) In V. kommen fast alle italienischen sdruccioli vor, in M. sind sie wenig zahlreich und leicht als italienische Eindringlinge

* erkennbar. Unter Nr. 4 allein fallen hunderte von Formen. Mit der Theorie von der fusion insensible kommt man hier nicht aus. „Dès qu'on franchit en un point quelconque la limite du parler mentonais, la transition est tout aussi marquée que celle que nous avons constatée en quittant le territoire vintimillois".

In la Turbie, sur la frontière de la principauté de Monaco, 1 commence brusquement l'idiome de Nice dont le caractère le plus frappant est que tous les mots, à très peu d'exceptions près, ont la forme d'oc: contractions, aphérèses, diphtongaison, tout est provençal. Die unterscheidenden Merkmale der Mundart von Nizza möge man bei Tourtoulon S. 166/67 nachsehen. Mit vollem Rechte darf man mit Tourtoulon die piemontesisch-provençalische Sprachgrenze zwischen Ventimiglia und Nizza ansetzen, wobei charakteristisch

1 Die Thatsache, dafs man in Monaco italienisch spricht und wie dieselbe zu erklären ist, hat mit unserem Thema nichts zu thun. 
ist, dafs der Übergang sich in zwei ${ }^{1}$ plötzlich auftretenden, unvermittelten Stufen vollzieht.2

Über die Beschaffenheit der provençalisch-piemontesischen Sprachgrenze auf dem Ostabhange der kottischen Alpen verdanke ich Herrn Professor W. Förster, der im Herbst 1887 jene Gegend bereiste (vgl. Ztschrift XVI 253), folgende Nachricht: „Die Sprachgrenze zwischen Piemontesisch und Provençalisch ist so scharf, wie ich sie anderswo zwischen Deutsch und Tschechisch und Deutsch und Italienisch angetroffen habe. Es sind keine Mischungen; es sind zwei Sprachen, die nicht unmerklich in einander übergehen, sondern streng wie Öl und Wasser geschieden sind".3 Eine genaue Aufnahme der Sprachverhältnisse in den einzelnen Grenzorten wäre auch hier erwünscht.

III.

Hiermit ist die Zahl derjenigen Dialektgrenzen erschöpft, deren Existenz bis jetzt nachgewiesen ist. 4 Auf einer grölseren Strecke ist überhaupt blofs die französich-provençalische Grenze festgestellt,

1 Da jede Sprachgrenze das Produkt eigenartiger historischer Faktoren ist, so ist von vorn herein wahrscheinlich, dals nicht zwei Sprachgrenzen genau dieselbe Beschaffenheit zeigen werden.

2 Von dieser Untersuchung Tourtoulons, die, man mag über die Dialektfrage denken, wie man will, einen wertvollen Beitrag zur romanischen Dialek. tologie bildet, sagt P. Meyer in der Besprechung Rom. 20, 323 kein Wort. Dagegen gibt er $T$. den Rat, er möge sich die Methode der Herren Gilliéron und Rousselot aneignen. Nach dieser Methode soll zunächst jedes sprach. liche Merkmal für sich gesondert verfolgt und aufgenommen werden. Wo indessen zwei oder wie in Mentone und Nizza eine grölsere Anzahl von Merkmalen zusammenfallen, da verlangt die wissenschaftliche Methode, dafs dies gebührend hervorgehoben werde. Dies hat Tourtoulon gethan, wie dies gewifs auch Gillieron und Rousselot gethan haben würden, wenn sie dasselbe Gebiet erforscht hätten. Der Unterschied zwischen Tourtoulon und Gilliéron liegt m. E. weniger in der Methode der Forschung, als in der verschiedenen Auffassung und Beurteilung der festgestellten sprachlichen Thatsachen.

3 Prof. Förster fügt hinzu: Nur dringt das Piemontesische stets siegreich vor und erobert einen Ort um den andern. Es geschieht dies auf demselben Wege wie in Böhmen, Görz, Tirol, Unter-Engadin: das Individuum wird zunächst zweisprachig und gibt dann die ursprüngliche Sprache auf. P. Meyer gibt Romania 20, 323 die Existenz von Sprachgrenzen da zu, wo ,un idiome a gagné du terrain au détriment d'un autre“. Er scheint anzunehmen, dafs die Sprachgrenze erst infolge des siegreichen Vordringens einer Mundart auf Kosten einer anderen zustande kommt. Dies ist an sich keineswegs evident oder auch nur wahrscheinlich. Wenn eine Mundart durch eine andere verdrängt wird wie die provençalische durch die piemontesische, so ist die Sprachgrenze nur dann scharf und deutlich, wenn schon vor dem Beginne dieses Processes zwischen beiden Mundarten zahlreiche und wichtige Unterschiede vorhanden waren. Sind die beiden Mundarten einander sehr ähnlich, so wird es, wenn die eine ein Übergewicht über die andere erlangt, zunächst zu einer Zersetzung der minder widerstandsfähigen kommen. Wie sich in diesem Falle eine eigentliche Sprachgrenze herausbilden soll, ist mir unklar.

- Der Umstand, dafs A. Thomas in seiner Untersuchung über die Mundarten der Creuse (vgl. darüber P. Meyer, Romania 8, 469) und Gilliéron in seinem Atlas phonétique du Valais roman auf keine Sprachgrenzen gestofsen 
von andern besitzen wir gleichsam nur Bruchstücke, über andere nur allgemeine Angaben, für welche allerdings zuverlässige Gewährsmänner einstehen, die jedoch durch kein philologisches Material verbürgt sind. Über Dialektgrenzen aufserhalb Frankreichs ist so gut wie nichts bekannt. ${ }^{1}$ Auch Italien, das in mancher Beziehung an der Spitze der romanischen Dialectologie steht, hat, abgesehen von den Forschungen Ascolis über das Franco-provençalische, m. W. keine Arbeit aufzuweisen, die den obengenannten an die Seite gestellt werden könnte. Was der Wissenschaft not thut, das ist die weitere Frforschung der Dialektgrenzen.2 Die Bedeutung derselben in dem Entwicklungsgange der romanischen Sprachen steht in direktem Verhältnis zu ihrer Zahl. Es zeigt sich hier an einem Beispiel, dals die Ideen, die allgemeinen Gesichtspunkte, erst dann richtig erfalst werden können, wenn der Stoff, aus dem sie gewonnen werden, möglichst vollständig vorliegt.

sind, ficht uns nicht an. Wir behaupten keineswegs, dafs überall Sprach. grenzen vorhanden seien. Dazu kommt, dafs Gilliéron und Thomas die Sprachgrenze als eine Linie auffassen. - Philipon hat, wie P. Meyer Romania 20, 323 bemerkt, nachgewiesen, dafs die von Puitspelu in willkürlicher Weise vorgenommene Abgrenzung eines angeblichen patois lyonnais in der That völlig in der Luft schwebt: Puitspelu hatte etwa 30 Ortschaften zu einer Gruppe vereinigt, ohne an Ort und Stelle auch nur die einfachsten Erhebungen vorgenommen zu haben. Mit dieser Widerlegung ist aber nicht einmal bewiesen, dafs es in dem Gebiete des alten Lyonnais (das etwa 200 Ortschaften umfafste) keine Sprachgrenzen gibt, denn dazu ist eine genaue, an Ort und Stelle vorgenommene, jede einzelne Ortschaft und möglichst zahlreiche sprachliche Merkmale berücksichtigende Untersuchung nötig. Eine solche Untersuchung hat Philipon nicht angestellt. - Romania 20, 323 sagt P. Meyer, dafs seine Roman. XX gedruckte Abhandlung über die Sprache von Die (Depart. Drôme) im I 3. Jahrh. „est en fait la confirmation la plus absolue des idées que conteste $M$. de Tourtoulon, puisque tous les caracteres linguistiques signalés ont des aires différentes". Auch hier muls ich widersprechen. Die Angaben Meyers, sofern sie sich nicht auf die Sprache vou Die selbst, sondern auf die der Umgegend beziehen, sind viel zu allgemein und lückenhaft, als dafs dadurch der Beweis erbracht wäre, dafs es in jener Re. gion keine Sprachgrenzen gibt. Die heutige Sprache ist so gut wie nicht in Betracht gezogen. Es kann aber nicht genug betont werden, dals der Ausgangspunkt und die Grundlage jeder derartigen Untersuchung die genaue Aufnahme des heutigen Sprachbestandes sein mufs. Meyer bemerkt S. 76, dals betontes $a$ nach Palatal zwischen St-Vallier und Vienne in e übergeht. Davon ist beispielsweise auszugehen: mit der Grenzlinie dieses $e$ müssen gleichzeitig die Grenzlinien der anderen (wenigstens der wichtigsten) Lauterscheinungen durch genaue Aufnahme in den einzelnen Ortschaften festgelegt werden. Es sind dann auch andere Faktoren (der frühere Zustand der Sprache, u. a.) zu berücksichtigen. Erst aus dem so gewonnenen Material lassen sich positive oder negative Schlüsse ableiten, die wissenschaftlichen Wert haben.

1 Nach Gartner Rätorom. Gramm. S. XXIII ist der Übergang vom Friaulischen zum Venetischen jäh.

${ }^{2}$ Methodische Winke geben Gröber Grundrifs I, 418 und Tourtoulon RdLR 34, 146, der das Mals des Verständnisses festzustellen suchte, das bei Leuten aus dem Volke für die angrenzenden und entfernteren Mundarten vorhanden ist. Wenn auch die Sprachgrenzen vielfach nicht mit politischen zusammenfallen, so ist der Fall auch nicht selten, dafs in der Nähe einer politischen Grenze sich eine Sprachgrenze findet.

Zeitschr. f, rom. Phil, XVII. 
Die Erforschung der Dialektgrenzen ist die Vorbedingung für die Beantwortung der Frage, die wir bis jetzt absichtlich nicht berührt haben, - ob es Dialekte gibt. Nach unserem Dafürhalten ist die Frage noch gar nicht spruchreif, und zwar deshalb, weil es an den nötigen Vorarbeiten fehlt. Wenn erst die pikardischwallonische Sprachgrenze in ibier ganzen Ausdehnung aufgenommen ist und es sich herausstellt, dafs sie in ihrem gesamten Verlaufe eine ähnliche Beschaffenheit zeigt wie der von Simon beschriebene Teil; wenn anderseits eine wallonisch-lothringische, die pikardisch-wallonische ohne Unterbrechung fortsetzende Dialektgrenze nachgewiesen ist, - dann, meinen wird, wird man mit Fug und Recht von einem wallonischen Dialekte reden dürfen. Ein Dialekt wäre demnach zu definiren: ein von allen Seiten durch Dialektgrenzen (resp. wie beim Wallonischen durch nichtromanische Sprachen) umschlossener und gleichsam isolirter Sprachcomplex. Die wesentliche Eigenschaft, die dieser Complex besitzen wird, ist eine relative historische Selbständigkeit. Es wurde bereits oben darauf hingewiesen, dafs Ascoli Archiv. glott. ital. III 6r dem Franco-provençalischen la sua propria indipendenza istorica vindicirt. Diese Selbständigkeit kann bestehen, ohne dafs der Dialekt sogenannte caractères spécifiques besitzt, ${ }^{1} \mathrm{~d} . \mathrm{h}$. solche, die ihm allein unter Ausschlufs aller anderen romanischen Mundarten angehören, wie dies Ascoli, Archiv. glott. ital. II 387 auseinandergesetzt hat: das Unterscheidende, Originelle eines bestimmten Dialekts „sta nella simultanea presenza o nella particolar combinazione di caratteri ripartiti in varia misura fra i tipi congeneri“. Diese Theorie der caractères spécifiques wird weiter unten noch in einem anderen Zusammenhange besprochen. - Indessen, wie gesagt, der Weg, den wir hier betreten, ist noch nicht gebahnt, und das Ziel entzieht sich daher unsern Blicken. Deshalb, und nur deshalb gehen wir auf die Frage nach der Existenz der Dialekte nicht weiter ein. Dieselbe läfst sich nach unserer Ansicht nicht aus allgemeinen, theoretischen Erwägungen heraus lösen, sondern nur auf empirischem Wege durch Beobachtung der Wirklichkeit.

Noch ein Wort über den Ausdruck Sprachgrenze als Gegensatz zu Mundartgrenze. Beide haben wir bis jetzt als gleichbedeutend gebraucht, und es bleibt unseres Erachtens subjektivem Ermessen anheimgegeben, ob man einer Mundartgrenze Wichtigkeit genug beimessen will, um derselben den Namen einer Sprachgrenze beizulegen. Dies gilt auch von der von Tourtoulon und Bringuier ermittelten linguistischen Grenze zwischen dem Provençalischen und dem Französischen. Berechtigt wäre man dann von

1 Gilliéron macht Romania 12, 394 gegen Joret geltend, qu' aucun des caractères étudiés n'appartient en propre à la Normandie, que le patois normand ne peut être spécifié ni par un ni par plusieurs caractères qui lui soient particuliers. Desgleichen tadelt es Marchot Ztschrift 16,550, dafs die von Simon behufs Festlegung der pikardisch - wallonischen Grenze aufgestellten Merkmale nicht als caractères spécifiques des Wallonischen gelten können. 
zwei verschiedenen Sprachen auf dem Boden Galliens zu reden, wenn sich nachweisen liefse, dafs die südfranzösischen Mundarten sämtlich von einem oder wenigen in Südfrankreich gelegenen Centren aus Verbreitung gefunden haben, während die nordfranzösischen in derselben Weise von einem oder wenigen in Nordfrankreich gelegenen Mittelpunkten ausgegangen wären. $\mathrm{Ob}$ indessen ein derartiger Nachweis je gelingen wird, steht dahin. ${ }^{1}$

Aus den obigen Ausführungen ist ersichtlich, in welchem Sinne wir Sprachgrenzen und eventuell Dialekte annehmen. Dagegen lehnen wir eine Einteilung der Sprache in sogenannte natürliche Gruppen ab (groupes et sous-groupes considérés comme des divisions naturelles comparables à celles de la zoologie et de la botanique in RdLR 33, 48). Es ist ein Verdienst P. Meyers, dafs er die Unhaltbarkeit dieses Standpunktes nachgewiesen hat. So etwas wie die Arten und Unterarten der Botanik gibt es in der Sprache nicht, einmal, weil die Sprachwissenschaft es nicht mit im Raum scharf abgegrenzten Individuen $z u$ thun hat, sodann aber weil die sogenannten Spracharten (Dialekte) in der Zeit nicht den Bestand und die Festigkeit (constance et fixité) besitzen, die den natürlichen Arten der Tiere und Pflanzen eignet. Jene Sprachcomplexe verändern sich unter allen Umständen viel schneller als die Arten der Botanik und Zoologie. Auch Schuchardt hat sich Litteraturbl. 13, 305 mit Recht gegen eine genealogische oder systematische Klassifizirung der Sprachen ausgesprochen und die Übertragung der Begriffe Race, Typus, Organismus auf die Sprache abgelehnt. ${ }^{2}$ "Die Sprache, sagt Schuchardt Über die Lautgesetze S. 34, ist kein natürlicher Organismus, sondern ein soziales Produkt."3 Gibt es eine systematische Klassifizirung der Sprachen, so müssen

1 Gröber sagt Grundrifs I, 419: Höhere Einheiten als jene Mundarten gibt es in der Sprache nicht. Neben den italienischen, französischen $\mathbf{M}$ undarten ist italienische, französische Sprache lediglich ein Gedankending ohne Dasein.

Verfehlt ist das Hereinziehen dieser naturwissenschaftlichen Gesichtspunkte bei J. Simon, Durand, Joret, Tourtoulon und andern. Fern zu halten sind alle jene images empruntées aux divers règnes de la nature, um einen Ausdruck Gilliérons zu brauchen.

s Schuchardt weist 1. c. S. 304 mit dem Satze von der Absolutheit der Lautgesetze auch den von der Klassifizirbarkeit der Mundarten zurück. Consequent ist er indessen nur, wenn er, wie eine absolute Lautgesetzmälsigkeit, so auch eine absolute, d. h. systematische, genealogische Klassifizierung verwirft. So gut es aber zwischen den absoluten Lautgesetzen und den einzelnen lautlichen Thatsachen für Schuchardt ein drittes gibt, nämlich empirische, relative Gültigkeit besitzende Lautgesetze, ebensogut müfste Sch. auch Sprachgrenzen resp. Dialekte in unserem Sinne annehmen, da dieselben etwas sind, das in der Mitte steht zwischen der absoluten Klassifizirbarkeit der Mundarten und dem einzelnen trait linguistique. Die Consequenz seines Standpunktes mülste ihn demnach zu unseren Ansichten führen und nicht zu denen von Paris, der solche Mittelglieder nicht anerkennt. Wenn Sch. bemerkt, dals er heute noch auf dem Standpunkte steht (es ist der Paris'sche), den er schon im Jahre 1870 einnahm, so hat er, wie es scheint, in den einschlägigen Forschungen Ascolis und Gröbers und in den neuesten dialektologischen Untersuchungen nichts zu lernen gefunden. 
auch die Sprachgrenzen gleichsam einen absoluten Charakter haben, sie müssen einer mathematischen Linie gleichkommen, denn sonst ist eine reinliche Scheidung der aneinander grenzenden Dialekte unmöglich; und anderseits muls sich jede Sprachgruppe von jeder andern durch eine Reihe von sogenannten caractères spécifiques unterscheiden, d. h. von solchen Merkmalen, die sich in keiner andern wiederfinden, denn nur auf diesen caractères spécifiques beruht ihre Existenzberechtigung. Beide Forderungen stehen und fallen mit der Annahme einer systematischen Klassifizirung.

Indessen, wenn Paris und Meyer mit Recht von einer sogenannten natürlichen oder systematischen Klassifizirung der Sprachen nichts wissen wollen, so haben sie anderseits über die Bedingungen, unter denen die Sprachen sich im Raume entwickeln, Ansichten, denen wir nicht beipflichten können und die für ihre Auffassung der Sprachgrenzen und der Dialekte von einschneidender Bedeutung sind. Die Patois sind nach Paris Parlers S. I 70 das Ergebnis de l'évolution spontanée du latin. Diese évolution hat sich in jedem Orte in selbständiger Weise vollzogen und ist durch die Race, die geographische Lage und das Klima bedingt. Demnach (S. 163) le parler d'un endroit contiendra un certain nombre de traits qui lui seront communs, par ex., avec le parler de chacun des quatre endroits les plus voisins, et un certain nombre de traits qui différeront du parler de chacun d'eux. Mit der Entfernung nehmen die Unterschiede allmählich zu, bis zuletzt das Verständnis aufhört. Es folgt hieraus, dafs (S. 164) d'un bout à l'autre du sol les parlers populaires étendent une vaste tapisserie, dont les couleurs variées se fondent sur tous les points en nuances insensiblement dégradées. Es ist ein sprachlicher Atomismus, auf den das Motto $\pi \dot{\alpha} \nu \tau \alpha \alpha \oint \varepsilon$ passen würde. P. Meyer hatte Romania 5, 505 gesagt: les variétés locales se fondent les unes dans les autres, sans qu'on puisse voir nettement où l'une commence et l'autre finit. Bei einer solchen Beschaffenheit der Sprache ist es ein thörichtes Unterfangen, da Grenzen ziehen zu wollen, wo die Natur keine kennt. Wer dies trotzdem thut, der handelt willkürlich; die Merkmale, nach denen man die Einteilung vornimmt, „on les choisira arbitrairement selon l'endroit où, d'après une idée préconçue, on voudra fixer la limite". (P. Meyer, Romania 4, 294). Une divisions suppose des limites, et le parler roman n'offre que des limites extérieures, là où il confine à la mer ou à des idiomes non latins. De limites intérieures, il n'en a pas (P. Meyer Romania 5, 505) und Romania 6, 631: les dialectes n'existent pas dans la nature à l'état défini, mais nous les constituons à notre guise pour la commodité de nos études. Doch gilt diese Theorie nach Paris (S. 164) nur von einem développement linguistique livré à lui-même, d. h. in dem die sprachliche Entwicklung sich ungestört nach natürlichen Gesetzen vollzieht. ${ }^{1}$

1 Auch Gilliéron spricht Roman. 12, 395 in demselben Sinne von einem état linguistique normal. 
Dans un pays civilisé qui a une histoire, les phénomènes naturels sont sans cesse contrariés par l'action des volontés. Il y a eu des influences exercées par des centres intellectuels et politiques... il y a eu des transplantations de populations. Doch sind diese Einwirkungen etwas secundäres, des faits accidentels, d'un ordre purement historique, welche dem état normal, résultat du libre développement du latin. (s. Roman. 6, 633) zuwider laufen. „Si le développement naturel n'avait pas été entravé par des actions politiques et littéraires, il n'y aurait sans doute pas aujourd' hui deux communes qui parleraient exactement le même latin" (Parlers S. 167). Das geschichtlich Gewordene wird demnach zu dem naturgemäls Entstandenen in einen Gegensatz gebracht, der das geschichtlich Gewordene als einen gewaltsamen, störenden Eingriff in die natürliche Entwicklung erscheinen lälst. Aus diesem Gesichtspunkte begreift man, dals P. Meyer Romania 6,631 die Möglichkeit zugibt, dafs il existe aujourd'hui une limite assez précise, là où jadis on l'aurait vainement cherchée; aber, dans les cas normaux, là où le développement linguistique n'a été troublé par aucune circonstance extérieure (vgl. Roman. 20, 323), on ne peut trouver des limites naturelles à un dialecte.

Diese Lehre von der Verteilung und Entwicklung der Sprache im Raume nach natürlichen Gesetzen (dem Leser wird die häufige Wiederkehr der Ausdrücke nature und naturel nicht entgangen sein), diese Theorie von einem „état de nature“ der Sprache, zu dem das historisch Gewordene in einen schroffen Gegensatz gebracht wird, - lehnen wir ab. Sie beruht unseres Erachtens auf unbewiesenen Voraussetzungen. Unbewiesen ist, dafs die patois in ihrer Mehrzahl spontane Produkte des Lateins in den Orten sind, in denen sie gesprochen werden. Voraussetzung hierfür ist eine gewisse Dichtigkeit der Bevölkerung. Aber Gallien war in den ersten Jahrhunderten nach der Völkerwanderung schlecht bevölkert, 1 die bewohnten Striche waren durch Einöden, Wälder ${ }^{2}$ von einander getrennt. Nithin wird in zahllosen Fällen eine Mundart sich nicht spontan an der Stelle entwickelt haben, wo wir sie heute finden, sondern sie wird ein fremdes Produkt sein, das erst dahin verpflanzt wurde. Eine sprachliche, von historischen Einflüssen unberührte Entwicklung, ein développement linguistique livré d

1 Nach E. Levasseur (La population française, 3 Bände, Arthur Rousseau, 1889) belief sich die Bevölkerung Frankreichs (das heutige Gebiet ist gemeint) zur Zeit der römischen Eroberung auf 6700000 Einwohner, auf 81/2 Millionen unter den Antoninen, auf 6-8 Millionen zur Zeit Karls des Grolsen, auf 20-22 Mill. in der ersten Hälfte des 14. Jhrh. (vgl. Revue des Deux-Mondes, Bd. 114 , S. 305).

2 Den von Gröber Grundrifs I 417 beigebrachten Zeugnissen fuige ich eins aus Joret, Des Caractères et de l'Extension du patois Normand S. 8 hinzu: Nach A. Le Prévost (Anciennes divisions territoriales de la Normandie, in - 4, 1860, S. 57) le Perche n'était qu'une forêt avant l'invasion normande. Zur ehemaligen Landschaft Perche gehörten die heutigen Departements Orne, Eure-et-Loir, Sarthe, Loir-et-Cher. 
lui-même ist ein bloIses Gedankenprodukt, etwas, das nie existirt hat und wovon man sich keine klare Vorstellung machen kann.1

Die ganze Entwicklung der Sprache im Raume ist für uns wesentlich, wenn nicht ausschliefslich durch historische Faktoren ${ }^{2}$ bedingt. Von der Sprache, sofern sie sich im Raume ausbreitet, gilt insbesondere das schon oben angeführte Schuchardtsche Wort: Die Sprache ist kein natürlicher Organismus, sondern ein sociales Produkt. - „Die Latinisirung einer römischen Provinz erfolgte notgedrungen von auseinander liegenden Orten aus" (Gröber l. c.), deren Sprachen sich durch gewisse Merkmale (mögen dieselben ursprünglich immerhin erst schwach entwickelt gewesen sein) von einander unterschieden. Eine jede Sprache breitete sich allmählich über die Umgegend aus; mit jeder neugegründeten Ortschaft erweiterte sich ihr Gebiet, und durch den beständigen Verkehr der Ortschaften unter einander wurde eine gewisse Gleichmärsigkeit der Entwicklung gesichert und dem Ganzen ein einheitliches Gepräge aufgedrückt. So bildeten sich auf historischem Wege gewisse Sprachtypen heraus, die allerdings keinen genealogischen oder systematischen Charakter an sich tragen, aber deshalb keine willkührlichen Erfindungen ordnungsliebender Pedanten sind. Wo solche Typen infolge ihrer wachsenden Ausbreitung sich berühren, da entstehen Sprachgrenzen, die ebenso wenig etwas willkürlich ersonnenes sind. Während nach Paris il n'y a place pour aucune division intermédiaire entre le patois d'une commune et la masse linguistique à laquelle il appartient, sind wir der Ansicht, dafs die Dialektgrenzen, die wir historische nennen, im Gegensatze zu den auch von uns nicht anerkannten natürlichen, gesetzmärsig (aber nach historischen Gesetzen) entwickelte Mittelglieder bilden zwischen den einzelnen Ortschaften und der romanischen Spracheinheit. 3

1 Tourtoulon sagt sehr richtig RdLR 34, 174: l'expérience de ce développement libre n'ayant pu être faite nulle part et les impulsions d'ordre physiologique et d'ordre psychologique, auxquelles le langage obéit, étant mal connues, on ignore absolument ce qui serait arrivé, si les peuples romans avaient pu soustraire leur parler à toute influence extérieure.

2 Der Verkehr in seinen verschiedenen Formen ist für uns der einzige Träger und Vermittler der Verbreitung der Sprache im Raume. Für manche Gelehrte ist, wie es scheint, bei dieser Verbreitung auch ein der Sprache inwohnendes lautphysiologisches Gesetz wirksam : so sagt Meyer-Lübke Roman. Gramm. I, 10: ,jeder Lautwechsel pflanzt sich von seinem Ausgangspunkte fort; er erweitert sein Territorium, verlärst dabei aber auch oft die Bedingung, an die er ursprünglich geknüpft war". Schuchardt Literaturblatt 13, 312 bemerkt, dafs ,eine sprachliche Erscheinung auf einem bestimmten Gebiete entweder mehr diffus oder mehr radiär ist... Hierv on ab ge sehen, beruht die Verbreitung auf dem Verkehr". Auch bei der Aufstellung der sogenannten Wellentheorie (vgl. dazu Grundrifs I 416) scheint von derselben Voraussetzung ausgegangen zu werden, die für uns unannehmbar ist, so lange nicht klar gesagt wird, in welcher Weise sich die betreffenden sprachlichen Vorgänge vollziehen sollen.

8 Wenn Paris Parlers S. 168 betont, man solle die Mundarten Frankreichs nicht d'après des divisions arbitraires et factices, sondern dans toute 
Es erübrigt noch, den schwerwiegendsten Einwand zu prüfen, wolcher gegen die Aufstellung von Sprachgrenzen und Dialekten in unserem Sinne erhoben worden ist. Man sagt: Die fünt oder sechs Merkmale, welche z. B. bei der Beschreibung der pikardischwallonischen Grenze als malsgebend hingestellt wurden, sind willkürlich ausgewählt. Nur deshalb, weil man sich bei der Auswahl derselben volle Freiheit vorbehält, gelingt es überhaupt, eine Sprachgrenze zu zeichnen, die mit einem gewissen Schein von Wahrscheinlichkeit als solche gelten kann. Wählt man andere Kriterien, so gelangt man zu anderen Ergebnissen. Berücksichtigt man z. B. den dem Wallonischen und Pikardischen gemeinsamen Laut $\hat{\varepsilon}=$ lat. $\left.e n^{k}\right)$, so ergibt sich eine andere Gruppirung. Folglich sind alle derartigen Einteilungen ein willkürliches Spiel mit beliebig ausgewählten Merkmalen. Les groupes, sagt Paris S. 170, qu'on est tenté de former se dissolvent ou se recomposent autrement suivant le critérium phonétique ou morphologique qu'on emploie à les constituer. ${ }^{1}$ Auf diesem Wege kommt Paris zu dem Ergebnis (S. 163), dafs dans une masse linguistique de même origine il n'y a réellement pas de dialectes; il n'y a que des traits linguistiques qui entrent respectivement dans des combinaisons diverses. Die Zahl, die Ausdehnung, die Grenzen der Gruppen ändern sich, je nachhem man diese oder jene, eine gröfsere oder eine geringere Anzahl Merkmale auswählt. P. Meyer hatte Romania 4, 295 gesagt: on pourra imaginer bien des manières de grouper les dialectes, chacune se fondant sur un certain choix de faits linguistiques et aucune n'échappant à l'inconvénient de tracer des circonscriptions là où la nature n'en connaît pas.

Es soll zunächst darauf aufmerksam gemacht werden, dafs auf Grund dieser Beweisführung jede Klassifikation, welcher Art sie auch

la richesse et la liberté de cet immense épanouissement zur Darstellung bringen, so hat man den Eindruck, als ob für Paris jeder Versuch zu klassifiziren zugleich ein Bemühen sei, der Sprache Gewalt anzuthun und die sich in ungebundener Freiheit entfaltenden Erscheinungen in Fesseln und in Formeln zu zwängen. Derselbe Einwand liefse sich gegen die wissenschaftliche Erforschung jedes beliebigen Gegenstandes erheben. Es handelt sich um Feststellung des gesetzmärsig Gewordenen in dem Mafse, in dem wir es zu erkennen vermögen - nicht mehr und nicht weniger. Schlimm ist es freilich, wenn die divisions arbitraires und factices sind. Aber wir bestreiten, dafs jede Einteilung diesen Charakter notwendig trage - darum dreht sich eben der Streit. - P. Meyer sagt Rom. 4, 295: le meilleur moyen de faire apparaitre sous son vrai jour la variété du roman, c'est d'indiquer sur quel espace de terrain règne chaque fait. Dem stimmen wir $z u$, wenn damit die Methode, nach welcher der Stoff gesammelt werden soll, bezeichnet wird, wenn damit die Vorbedingungen für jedes tiefere Eindringen in den Gegenstand angegeben werden. Soll dagegen mit jenen Worten das Ziel der Forschung selbst bezeichnet werden, so müssen wir unsere Vorbehalte machen, denn das Ziel jeder Wissenschaft ist für uns die Erkenntnis eines kausalen $\mathrm{Zu}$ sammenhanges zwischen den Erscheinungen.

1 Ganz in diesem Sinne sagt Gauchat, Ztschrift 14, 398, Tafel I: on peut choisir les faits phonétiques de manière à faire croire à une topographie des dialectes. Mais ce serait une fausse conclusion. 
sein mag, als unberechtigt erscheinen mufs. Angenommen nämlich der Dialekt A unterscheide sich durch rehn Merkmale von dem Dialekte B und die Scheidung sei eine so scharfe, dals die Ausbreitungsflächen dieser zehn Merkmale sich genau decken, während die Ausbreitungsflächen der Merkmale, die B eigen sind, ebenfalls vollständig zusammenfallen. Auch gegen diese anscheinend vollkommene dialektische Abgrenzung liefse sich der Paris'sche Einwand mit demselben Rechte wie gegen jede andere weniger vollkommene ins Feld führen. Legt man, so liefse sich einwenden, statt der Merkmale I-IO von A die Merkmale II-I5 zu Grunde, die A mit B gemein hat, so erhält man eine verschiedene Gruppirung, die auch einen Teil von $B$ umfassen würde. Folglich sind die Gruppen A und B Produkte einer willkürlichen Combination.

Das Irrige der Paris'schen Schlufsfolgerung liegt für uns darin, dafs die gesammte Masse der traits linguistiques, so wie sie heute vorliegt, für die Einteilung und die Erkenntnis als gleichwertig betrachtet wird. Auf die historischen Bedingungen, auf die Zeit ihres Entstehens wird nicht eingegangen. Es ist noch immer der Standpunkt der abstract - logischen, systematischen Klassifizirung. ${ }^{1}$ Für uns ist eine Sprachgrenze (um von Dialekten hier nicht zu reden) etwas zeitlich bedingtes, das nicht immer war und nicht immer sein wird. Wer es ablehnt, auf die zeitliche Aufeinanderfolge der Erscheinungen einzugehen, der scheidet aus der ganzen Frage dasjenige aus, worauf es eben vorzugsweise ankommt. Angenommen die pikardisch-wallonische Sprachgrenze sei im I2. Jahrhundert dadurch entstanden, dafs die pikardischen und wallonischen Sprachcomplexe mit einander in Berührung kamen, so können als unterscheidende Merkmale nur diejenigen in Frage kommen, durch die damals beide Complexe sich von einander unterschieden. Als beide Sprachtypen sich in der oben angegebenen Weise allmählich differenzirten, so blieben viele althergebrachte, beiden Gruppen gemeinsame Merkmale (z. B. $e>$ lat. $a, \tilde{\epsilon}>$ lat. enkons.) von dieser Differenzirung unberührt. Legten wir unserer Einteilung jene ältesten Züge zu Grunde, so würden wir das unbeachtet lassen,

1 Auf diesem Standpunkte steht im Ganzen auch H. Paul, der in seinen Principien der Sprachgeschichte ${ }^{2}$ S. 40 z. B. sagt: "Ziehen wir in einem zusammenhängenden Sprachgebiete die Grenzen für all e vorkommenden dialektischen Eigentümlichkeiten, so erhalten wir ein sehr complicirtes System mannigfach sich kreuzender Linien. Eine reinliche Sonderung in Hauptgruppen, die man wieder in so und so viel Nebengruppen teilt, ist nicht möglich". In anderen Stellen kommt der historische Gesichtspunkt zur Geltung, doch ohne rechte Consequenz und Klarheit. - In seiner Etude sur les Changements Phonétiques stellt sich Paul Passy auf den Paris'schen Standpunkt, doch meint er $\mathrm{S}$. 18 ,partout où il y a une barrière naturelle un peu importante, les dialectes se séparent nettement" (nach P. Meyer Roman. 5, 504 le cas où un fait physique établit une limite est peu fréquent). Interessant ist die Thatsache, dals die Mundarten der Pikardie und der Ile-de-France scharf von einander geschieden sind, „depuis les environs de Creil jusqu'au delà de Verberie, par le cours de l'Oise, à tel point que les habitants des deux côtés de la rivière ont quelque peine à se comprendre". 
was die Hauptsache ist, die mit der Zeit eingetretenen Unterschiede zwischen beiden Complexen, es würde die historische Thatsache ignorirt, auf deren Feststellung es allein ankommt. Es würde in diesem Falle der sprachliche Zustand zur Darstellung kommen, welcher der Differenzirung vorausging, während der Name Sprachgrenze eben die Bezeichnung ist für die in bestimmter Zeit auftretenden, durch zusammenwirkende Ursachen bedingten sprachlichen Unterschiede. Wir wählen bestimmte Züge (z. B. $k a>$ lat. $c a, \check{s}>$ lat. $c e, s$ vor Kons. u. s. w.), weil sie allein jene historische Thatsache zum Ausdruck bringen, und deshalb ist die Auswahl keine willkürliche. Ein leeres Spiel wäre es nur dann, wenn wir Grenzen ansetzten, ohne uns auf diesen historischen Standpunkt zu stellen. Dafs bei einem derartigen Verfahren Irrtümer unvermeidlich, zahlreiche Fragen schwer zu lösen, andere vielleicht unlösbar sein werden, dies alles können wir zugeben, ohne dafs dadurch das Ziel der Wissenschaft verrückt werde.

Wie es Merkmale gibt, die älter sind als die Zeit, in welche die Entstehung jener Sprachgrenzen fällt, so gibt es auch wieder solche, die jünger sind. Wir behaupten nicht, dafs jene Sprachgrenzen für alle Zeiten sich ihre historische Selbständigkeit wahren werden. Es mögen sich neuerdings sprachliche Prozesse herausbilden, die jene Sprachgrenzen durchkreuzen und mit der Zeit vielleicht völlig aufheben. Es wird aber dadurch an der Thatsache ihrer einstigen historischen Selbständigkeit nichts geändert. So, z. B. gibt es im Lothringischen gewisse $\alpha$-Laute, die sich über Teile der von mir mit A, B, C bezeichneten Gruppen erstrecken. Der Einwand, dafs, wenn man dieses Merkmal zum Einteilungsprinzip machte, eine ganz andere Gruppirung zu stande kommen würde, ist deshalb nicht stichhaltig, weil sich diese $\mathscr{c}$-Laute erst neuerdings herausgebildet haben, nachdem jene Gruppenbildung vielleicht Jahrhunderte bestanden hatte. Durch die spätere Entwicklung kann die relative Selbständigkeit einer früheren Entwicklung als historische Thatsache nicht in Frage gestellt werden. ${ }^{1}$ Es ist demnach ein unwissenschaftliches Verfahren, wenn Gauchat Ztschrift 14, 348 auf dem Grunde einer Untersuchung des heutigen Lautstandes weniger Ortschatten, wobei von jeder historischen Kritik abgesehen wird und alle Lauterscheinungen als gleichwertig betrachtet werden, den Schlufs aufbaut, dafs es so etwas wie Dialekte nicht gebe und dafs allein die ,topographie des faits linguistiques pris isolément' eine Realität besitze.

Die Bedingungen, unter denen sich die Volkssprachen heute entwickeln, sind wesentlich von denjenigen verschieden, denen sie

1 So macht es Joret wahrscheinlich, dafs die Grenzen von ca und ce in der Normandie, die heute zum Teil divergiren, einst zusammenfielen, und auch Gilliéron scheint Rom. 12, 40 I zuzustimmen. Hier hätte demnach früher eine coïncidence bestanden, die heute verwischt ist. Für uns ist freilich jene coïncidence nicht fortuite, kein Spiel des Zufalles. 
im Mittelalter unterworfen waren. Im Mittelalter (wenn anders die Hypothese über die Sprachcentren Anspruch auf Wahrscheinlichkeit erheben darf), gravitirte die ganze Bewegung um gewisse Mittelpunkte, die bald eine centrifugale, bald eine centripetale Kraft ausübten. Heute liegen die Dinge anders: Die Bevölkerung hat sich bedeutend vermehrt, die Verkehrsverhältnisse wurden völlig umgestaltet. Der Verkehr auch zwischen den noch Patois redenden Orten wird immer mehr durch die Schriftsprache vermittelt. ${ }^{1}$ Die Folge ist, dafs diese Mundarten immer mehr sich selbst überlassen bleiben. Neuerdings entstandene Lautprozesse kreuzen vielfach die vor Jahrhunderten entstandenen Sprachgrenzen und bedrohen sie in ihrer Existenz. Wenn es überhaupt einen Zustand der Sprache gibt gleich dem, den Paris un développement linguistique livré à lui-même nennt, so suchen wir denselben nicht in der Vergangenheit, gleichsam in der Entstehungszeit der Mundarten, sondern weit eher in der Zukunft, als letztes Ziel der sprachlichen Entwicklung oder Aufösung der Patois.

Ist unsere Auffassung der Aufgaben der Dialektforschung richtig, so bestehen die engsten Beziehungen und Wechselwirkungen zwischen der allgemeinen Geschichte und der Dialektologie: beide Wissenschaften fördern einander gegenseitig und arbeiten einander in die Hände. Durch die eigenartige Gruppirung der Mundarten in den Vogesen ist z. B. die historische Thatsache ermittelt worden, dafs die romanische Colonisation nicht von Norden oder Süden, sondern von Westen über die Berge des Wasgau vordrang, und zwar ging der Anstofs hierzu von verschiedenen Punkten aus: nur so erklären sich die bedeutenden sprachlichen Unterschiede zwischen den verschiedenen Gruppen und ihre scharfe Abgrenzung. Es kam der Augenblick, wo die verschiedenen Ausbreitungsfächen mit einander in Berührung traten, und so bildeten sich die heutigen Sprachgrenzen. Diese historischen Vorgänge werfen anderseits Licht auf manche sprachliche Erscheinungen, so z. B. auf den auffälligen Wechsel zwischen der Monophthongirung und der Diphthongirung von betont. $\varepsilon, e, Q$, welcher vor allem die verschiedenen Gruppen kennzeichnet. Jener Wechsel erklärt sich daraus, da/s unter denjenigen französischen Ortschaften, von denen die Colonisirung ausging, die einen bereits den Monophthong durchgeführt hatten, während die andern noch an dem Diphthong festhielten. Die sprachlichen Begrenzungen verlieren so, um mit Schuchardt Literaturbl. 13, 319 zu reden, den Anschein der Zufälligkeit; wir lernen die Bedeutung der räumlichen Grenzen der Spracherscheinungen erkennen. Freilich sind uns damit die letzten Gründe noch nicht erschlossen, warum die Produkte von $e, \&, q$ nur in gewissen Gegenden zum Monophthong übergingen; aber es ist eine wichtige Vorfrage gelöst. Denn wenn es jemals gelingen

1 Immer seltener wird auch der von Gilliéron Roman. 12, 397 erwähnte Fall werden, qu'il y a des patois qui en absorbent d'autres en vertu d'une affinité sociale. 
soll, die tieferen Bedingungen jenes Wandels klarzulegen, so mufs zuvor festgestellt sein, in welchen Ortschaften sich jene Monopthongirung selbständig vollzogen hat und in welche Gegenden sie als fertiges lautliches Produkt durch den Verkehr eingeführt wurde. - Auch über das relative Alter der Lautwandlungen kann uns jene dialektische Gestaltung Aufschlufs geben: die Frage wurde schon oben in Bezug auf gewisse $\alpha$-Laute aufgeworfen. Aber auch für das Alter der erwähnten Monophthongirung werden Anhaltspunkte gewonnen, wenn es gelingt, die Zeit zu bestimmen, in welche der Beginn der Romanisirung der östlich von den Vogesen gelegenen Striche fällt. Auf diesem Wege wird es vielleicht auch gelingen, das Dunkel aufzuhellen, das über der Entstehung und Ausbreitung des Wandels von $c l, p l$, u. s. w. zu $c y, p y$ und von iss zu $\chi, \grave{s}$ liegt.

Zum Schlufs sei es gestattet, die Geschichte der Frage, welcher dieser Artikel gewidmet ist, kurz zusammenzufassen: Es gebührt P. Meyer das Verdienst, das Problem mit Schärfe gestellt, falsche Lösungen, sofern sie die Klassifizirung der Sprachen mit derjenigen der Naturwissenschaften identifizirten, abgelehnt und durch nachdrückliche Betonung der richtigen, bereits von Ascoli befolgten Methode (faire la géographie des traits linguistiques) die dialektologische Forschung bedeutend gefördert $\mathrm{zu}$ haben. Klärend wirkte auch Schuchardt durch den Hinweis, dals die Sprache in ihrer räumlichen Ausbreitung kein natürlicher Organișmus, sondern eine Funktion, ein soziales Produkt sei. So sehr wir indessen die Verdienste P. Meyers und Paris nach dieser kritisch-methodischen Seite anerkennen, so vermögen wir doch ihren Ansichten, sofern sie die positive Seite der Frage betreffen, nicht beizupflichten. Der Keim der richtigen Lehre liegt für uns nach dieser Seite in dem Worte Ascoli's von der (relativen) historischen Selbständigkeit, die er für das Franko-Provençalische in Anspruch nimmt. Es gab dann Gröber in seiner Centrentheorie wichtige Fingerzeige, auf welche Weise man sich eine solche sprachliche Selbständigkeit entstanden und bedingt zu denken habe. Endlich haben neuerdings angestellte dialektologische Untersuchungen das Ergebnis zu Tage gefördert, dals es Mundartgrenzen gibt. Die Thatsache der Existenz von Dialektgrenzen, die nach historischen Gesetzen entstandene Mittelglieder zwischen den einzelnen traits linguistiques und dem gesamten linguistischen Complex der romanischen Sprachen sind, darf jetzt als gesichert betrachtet werden, mögen die Ansichten über Wesen und Entstehung derselben noch so sehr auseinandergehen. Die $F_{1}$ age, ob es historisch selbständig entwickelte Dialekte gibt, wird sich hingegen erst dann beantworten lassen, wenn genaue und umfassende Aufnahmen einer grölseren Anzahl von Sprachgrenzen vorliegen.

\section{A. HORNING.}

